\title{
The role of Notch signaling in the mammalian ovary
}

\author{
Dallas A Vanorny and Kelly E Mayo \\ Department of Molecular Biosciences and Center for Reproductive Science, Northwestern University, \\ Evanston, Illinois, USA
}

Correspondence should be addressed to K E Mayo; Email: k-mayo@northwestern.edu

\begin{abstract}
The Notch pathway is a contact-dependent, or juxtacrine, signaling system that is conserved in metazoan organisms and is important in many developmental processes. Recent investigations have demonstrated that the Notch pathway is active in both the embryonic and postnatal ovary and plays important roles in events including follicle assembly and growth, meiotic maturation, ovarian vasculogenesis and steroid hormone production. In mice, disruption of the Notch pathway results in ovarian pathologies affecting meiotic spindle assembly, follicle histogenesis, granulosa cell proliferation and survival, corpora luteal function and ovarian neovascularization. These aberrations result in abnormal folliculogenesis and reduced fertility. The knowledge of the cellular interactions facilitated by the Notch pathway is an important area for continuing research, and future studies are expected to enhance our understanding of ovarian function and provide critical insights for improving reproductive health. This review focuses on the expression of Notch pathway components in the ovary, and on the multiple functions of Notch signaling in follicle assembly, maturation and development. We focus on the mouse, where genetic investigations are possible, and relate this information to the human ovary.

Reproduction (2017) 153 R187-R204
\end{abstract}

\section{Introduction}

The mammalian ovary is a female organ critical for reproductive function that contains and supports the development of the female gamete, the oocyte. The functional unit of the ovary, the ovarian follicle, forms a specialized niche necessary for the development of a mature oocyte and is also essential for the production of steroid hormones that drive reproductive function and support female health. During embryonic development, primordial germ cells (PGCs), which arise within the proximal epiblast, migrate to the genital ridges of the bipotential gonad, at that time, under the influence of signals from surrounding somatic cells, they develop into either sperm or oocytes (McLaren 1984, Saitou \& Yamaji 2012). During ovarian development, PGCs undergo several rounds of synchronous mitotic division without complete cytokinesis to form clusters of interconnected germ cells called germ cell syncytia, also known as cysts or nests (Pepling \& Spradling 1998). Though the function of germ cell syncytia has not been established, these structures provide a shared local environment to respond to stimuli and to allow the exchange of macromolecular resources (Pepling \& Spradling 1998). Following the induction of stimulated by retinoic acid gene 8 (Stra8) expression by retinoic acid, germ cells within the developing female gonad cease mitotic division and enter meiosis in an anterior to posterior wave across the ovary, arresting at the diplotene stage of meiotic prophase I (Menke et al. 2003, Koubova et al. 2006, Anderson et al. 2008).

Interactions between germ cells and somatic pregranulosa cells are critical for the formation of ovarian follicles. Perinatally in mice, and embryonically in humans, somatic pregranulosa cells send cellular projections around individual germ cells within fragmenting syncytia to encapsulate and form primordial follicles through the coordination of syncytial breakdown and follicle assembly in a process known as follicle histogenesis. This process involves bidirectional communication between germ cells and somatic support cells and it has been shown to be regulated by steroid hormone signaling, neutrophins, KITL/KIT signaling and members of the transforming growth factor-beta (TGF $\beta$ ) superfamily. Follicle histogenesis is also associated with significant levels of germ cell loss (Pepling 2012), which may serve to eliminate defective germ cells or provide a means to fragment syncytia (Pepling \& Spradling 2001). Aberrations in follicle histogenesis can result in the formation of multi-oocytic follicles, which are a consequence of incomplete fragmentation of syncytia, and in oocyte or follicle loss due to errors in follicle assembly (Silva-Santos \& Seneda 2011). Notably, follicle histogenesis results in the formation of the primordial follicle pool, which represents the entirety of oocytes available during a female's reproductive life. 
Table 1 Expression of Notch signaling components in the mammalian ovary.

\begin{tabular}{|c|c|c|c|c|c|c|c|c|c|}
\hline Gene & Oocyte & Prim & $1^{\circ}$ & $2^{\circ}$ & Antral & $\mathrm{CL}$ & Theca & Vasc & OSE \\
\hline Notch1 & 1,2 & 1 & & & & $3-5$ & & $3,6-9$ & 10 \\
\hline Notch2 & $4,11-13$ & $4,11,13,14$ & $4,11-14$ & $4,6,8,12-14$ & $4,6,8,12-14$ & 4 & 4 & & \\
\hline Notch3 & & & 4 & 4,6 & 4,6 & $4,6,15$ & 4 & & \\
\hline Notch4 & & 7 & 7 & 7 & 7 & 3,7 & & $3,6,7$ & 7 \\
\hline Jag1 & $4,6,11-14,16$ & 4 & 4 & 4,13 & & 4,15 & & 7 & \\
\hline Jag2 & 1 & & & 6 & 6 & & & & \\
\hline D/l1 & & & & 4 & & 4 & & & \\
\hline \multicolumn{10}{|l|}{ DII3 } \\
\hline D/l4 & 4 & 4 & 4 & 4 & 4 & 3,4 & & 3,9 & \\
\hline Hes 1 & 4,11 & 4,11 & 4 & 4 & & 4 & 4 & & 10 \\
\hline Hes5 & 4 & 4 & 4 & 4,6 & 4,6 & 4 & & & 10 \\
\hline \multicolumn{10}{|l|}{ Hes 7} \\
\hline Hey 1 & 12,17 & 17 & 12 & 6,12 & 6,12 & & & & \\
\hline Hey 2 & 11,12 & 11 & 12 & 6,12 & 6,12 & & & & \\
\hline Heyl & & & & 6 & 6 & & & & \\
\hline Lfng & & & & 18 & 18 & & & 18 & \\
\hline Mfng & & & & & & & & 18 & \\
\hline Rfng & & & & & 18 & & & & \\
\hline
\end{tabular}

References: (1) Guo et al. 2012, (2) Feng et al. 2014, (3) Hernandez et al. 2011, (4) Murta et al. 2014, (5) Accialini et al. 2015, (6) Johnson et al. 2001, (7) Vorontchikhina et al. 2005, (8) Jovanovic et al. 2013, (9) Garcia-Pascual et al. 2013, (10) Pan et al. 2015, (11) Trombly et al. 2009a,b, (12) Zhang et al. 2011, (13) Wang et al. 2014, (14) Vanorny et al. 2014, (15) Wang et al. 2015, (16) Dorfman et al. 2011, (17) Manosalva et al. 2013, and (18) Hahn et al. 2005.

$1^{\circ}$, primary follicles; $2^{\circ}$, secondary follicles; CL, corpora lutea; OSE, ovarian surface epithelium; Prim, primordial follicles; vasc, vasculature.

Following puberty, and during each estrous cycle in rodents or menstrual cycle in humans, a cohort of follicles is recruited to undergo further growth and maturation. Early stages of follicle activation and development are generally considered to be gonadotropin-independent, while later stages, including antrum formation, cumulus expansion and ovulation, require follicle stimulating hormone (FSH) and luteinizing hormone (LH). Following the release of a meiotically competent oocyte, remaining granulosa and theca cells of a follicle luteinize to form a corpus luteum, which is essential for the production of steroid hormones needed to prepare the uterus for pregnancy. In addition, there is rapid neovascularization of blood vessels within the theca layer to support this process.

The Notch pathway is one of the most conserved signaling systems in multicellular organisms, and perturbations in Notch signaling are responsible for a number of inherited human diseases and cancers (Maillard \& Pear 2003, Leong \& Karsan 2006, Penton et al. 2012). While the function of the Notch pathway in ovarian development has been extensively studied in model organisms such as Drosophila and C. elegans (Andersson et al. 2011, Greenwald \& Kovall 2013), there is limited information available on the function of Notch signaling in the mammalian gonad, and only recently have reports become available implicating Notch signaling in ovarian (Manosalva et al. 2013, Xu \& Gridley 2013, Vanorny et al. 2014) or testicular (Tang et al. 2008, Garcia \& Hofmann 2013, Huang et al. 2013) development. Within the mammalian ovary, Notch receptors, ligands, modulators and target/ effector genes are expressed and dynamically regulated during follicular development (Table 1). Activation of the Notch pathway has been described in both germline and somatic cell populations, and new studies involving the use of transgenic reporter mice and conditional knockout mouse models suggest that productive Notch signaling occurs between germ cells and granulosa cells, between adjacent granulosa cells, and between cells of the ovarian vasculature.

Morphogenesis of the mammalian ovary requires the precise spatial and temporal organization and function of multiple cell types, and is coordinated by endocrine, paracrine, autocrine and juxtacrine signaling mechanisms. The actions and regulation of paracrine and endocrine hormone signaling within the ovary has been extensively studied (Albertini et al. 2001, Knight \& Glister 2006, Edson et al. 2009, Conti et al. 2012); however, the roles of juxtacrine signaling within the ovary remain largely unexplored. This review will focus on the Notch pathway, a juxtacrine or contact-dependent signaling system, during ovarian and follicular development.

\section{Notch pathway signal transduction and regulation}

The Notch signaling pathway (Fig. 1) is a highly conserved and broadly used molecular transduction system for processes including cell-fate specification (Lindsell et al. 1996, Weijzen et al. 2002, Chau et al. 2006, Raetzman et al. 2006, Hayashi \& Kume 2008, Doetzlhofer et al. 2009), cell migration (Jordan et al. 2000), mesenchymal/epithelial transition (Li et al. 1998), cell survival/death (Nickoloff et al. 2002, Sainson et al. 2005, Choi et al. 2008), cell division (Sainson et al. 2005, Kolev et al. 2008, Monahan et al. 2009) and 
A

Notch receptors

EGF

LNR RAM ANK TADPEST

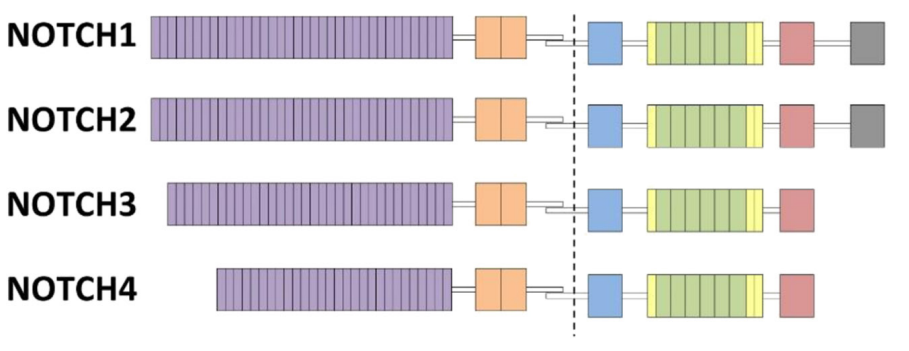

B Notch ligands

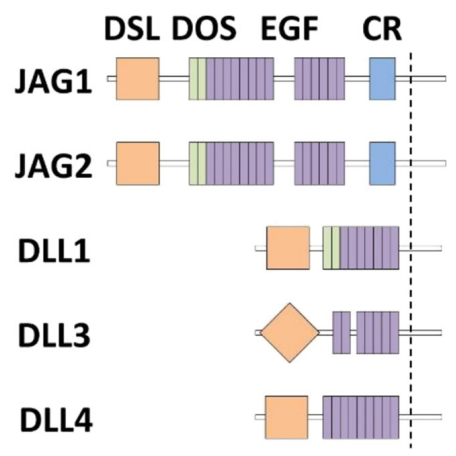

C

Notch signaling pathway

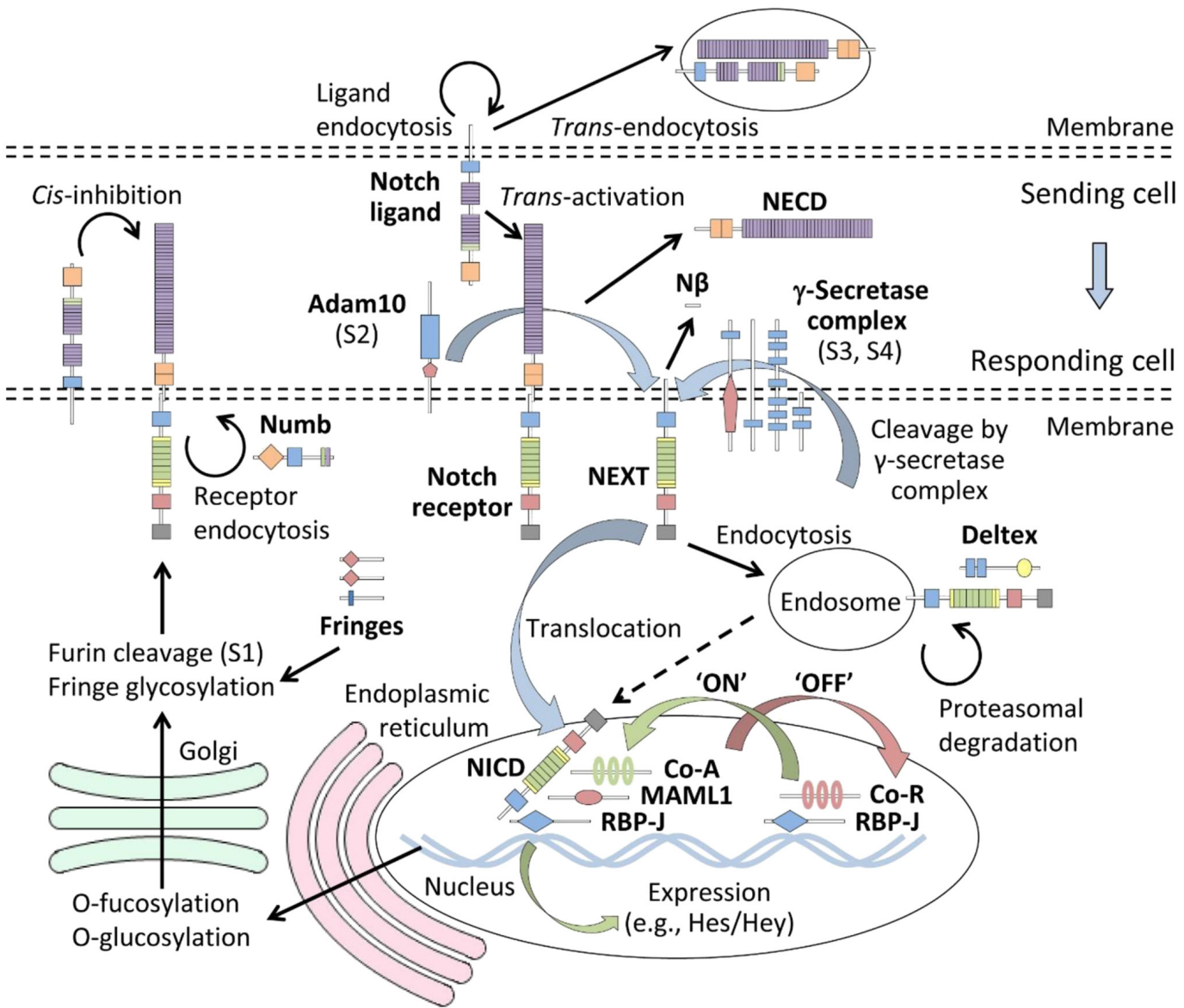

Figure 1 The Notch signaling pathway. In mammals, there are (A) four Notch receptors and (B) five Notch ligands. Extracellular interactions between receptors and ligands expressed on juxtaposed cells are mediated by several conserved domains. Among these are epidermal growth factor (EGF) repeats found on both ligands and receptors, LIN-12/Notch repeat (LNR) domains that are found on all receptors, and a highly conserved Delta-Serrate-Lag2 (DSL) domain found on ligands. Notably, the DSL domain of DLL3 is structurally divergent from that of other Notch ligands and does not promote Notch receptor activation. JAG1 and JAG2 also contain a cysteine-rich (CR) domain, while DLL3 and DLL4 lack a Delta and OSM-11 (DOS) domain composed of atypical EGF repeats. (C) Productive interactions between juxtaposed cells lead to the cleavage of Notch receptors at the juxtamembrane region by the $\gamma$-secretase complex. Nuclear localization signals (yellow bars) within the intracellular domain of Notch receptors (NICD) allow for nuclear translocation following receptor cleavage. The RBP-J associated molecule (RAM) domain facilitates interactions between the intracellular domain and the DNA-binding factor RBP-J. Binding of the NICD with RBP-J displaces corepressors (Co-R) and allows for the recruitment of transcriptional coactivators (Co-A) via interactions with CDC10/ankyrin (ANK) repeats and a trans-activation domain (TAD). Target or effector genes of the Notch pathway include the Hes and Hey families of transcriptional repressors. Notch signaling is terminated by ubiquitination of a proline-glutamate-serine-threonine (PEST) domain that targets the intracellular domain for proteasomal degradation. 
cell adhesion (Choi et al. 2008). Disruption of Notch signaling results in multiple human diseases including Alagille syndrome (Oda et al. 1997), familial aortic valve disease (Garg et al. 2005), Adams-Oliver syndrome (Stittrich et al. 2014), Hajdu-Cheney syndrome (Simpson et al. 2011), spondylocostal dysostosis (Bulman et al. 2000), cerebral autosomal dominant arteriopathy with subcortical infarcts and leukoencephalopathy (CADASIL) (Joutel et al. 1996), Alzheimer's disease (Kopan \& Goate 2000), and cancers including T-cell acute lymphoblastic leukemia (Weng et al. 2004) and pancreatic (Mullendore et al. 2009), colon (Reedijk et al. 2008) and ovarian cancers (Groeneweg et al. 2014).

Notch signaling is frequently used to select among pre-existing cellular potentials to specify cell-fate decisions. The two classical modes by which Notch signaling functions to mediate cell-fate decisions include lateral inhibition and inductive signaling (Flores et al. 2000, Haines \& Irvine 2003). Lateral inhibition is a mechanism by which a cell that adopts a particular fate inhibits neighboring cells from developing in a similar manner. By contrast, inductive signaling is a mechanism by which one cell, or a group of cells, remains in its current state, and signals to and causes a neighboring cell, or group of cells, to differentiate.

In mammals, the Notch pathway (ArtavanisTsakonas et al. 1999, Mumm \& Kopan 2000, Kopan 2002, Schweisguth 2004, Ehebauer et al. 2006) involves the interaction of one of four heterooligomer (Blaumueller et al. 1997) single-pass type I transmembrane receptors (NOTCH1, NOTCH2, $\mathrm{NOTCH} 3$ and $\mathrm{NOTCH} 4$ ) with one of five single-pass type I transmembrane ligands (JAG1, JAG2, DLL1, DLL3 and DLL4). Notch receptors contain 29-36 $\mathrm{N}$-terminal epidermal growth factor (EGF) repeats, of which EGF repeats 11-12 are essential for ligand binding, while Notch ligands contain a conserved N-terminal Delta-Serrate-Lag2 (DSL) domain, which is important for mediating interactions with Notch receptors. Notably, transmission of Notch signaling utilizes a unique mechanism mediated through a series of sequential proteolytic cleavage events that does not involve amplification by classical intracellular secondary messengers.

Following their synthesis, Notch receptors are post-translationally modified through fucosylation by protein O-fucosyltransferase 1 (POFUT1) within the endoplasmic reticulum. The receptors are further modified within the Golgi by the GlcNAc-transferase proteins lunatic (LFNG), manic (MFNG) and radical fringe (RFNG), which function to modulate receptorligand interactions. During their transit through the Golgi, Notch receptors are cleaved by the furin-like protein proprotein convertase subtilisin/kexin type 5 (PCSK5) at site 1 (S1) during exocytosis, which regulates receptor trafficking and signaling activity
(Logeat et al. 1998). The two receptor cleavage products remain associated at the cell surface as a heterodimer through non-covalent, calcium-dependent interactions (Gridley 2003). Importantly, the S1 cleavage site is contained within a critical negative regulatory region (NRR) of the receptor that is comprised of three highly conserved Lin-12/Notch repeat (LNR) domains and a heterodimerization domain (HD), which cooperate to prevent premature signaling in the absence of a ligand (Gordon et al. 2009).

Productive interactions between the extracellular domains of Notch ligands and receptors occur intercellularly in trans (i.e., trans-activation) between juxtaposed cells, whereas inhibitory interactions occur between receptors and ligands coexpressed along the membrane of the same cell in cis (i.e., cis-inhibition). As a consequence of trans-activating interactions, Notch receptors undergo a conformational change that exposes the site 2 (S2) cleavage moiety that is recognized by a disintegrin and metalloproteinase domain-containing protein 10 (ADAM10). The remaining membraneanchored Notch extracellular truncation (NEXT) fragment is recognized by the $\gamma$-secretase complex, an enzymatic assemblage composed of presenilin 1 (PSEN1), nicastrin (NCSTN), presenilin enhancer 2 (PEN2) and anterior pharynx-defective 1 (APH1) (Saxena et al. 2001). Further proteolytic processing at the juxtamembrane region of the Notch receptor by the $\gamma$-secretase complex at site 3 (S3) and site 4 (S4) results in the release of the Notch intracellular domain (NICD) and $N \beta$ peptide, which allows the NICD to translocate to the nucleus where it acts as a modulator of transcription (Fortini 2002).

Within the nucleus, the NICD interacts with the DNAbinding transcriptional repressor recombination signal binding protein for immunoglobulin kappa $\mathrm{j}$ region (RBP-J), also known as $\mathrm{CBF} 1 / \mathrm{Su}(\mathrm{H})$, through its RBP-J associated molecule (RAM) domain (Lubman et al. 2007). Subsequently, this interaction positions CDC10/ ankyrin repeats within the NICD to recruit transcriptional activators, such as mastermind-like proteins (MAMLs), to the promoters of Notch target genes. Classic target genes of Notch signaling include the hairy/enhancerof-spilt (Hes) and hairy/enhancer-of-split related with YRPW motif protein (Hey) genes, which are members of the basic helix-loop-helix (bHLH) family and function as transcriptional repressors. The ankyrin repeats of Notch receptors also facilitate interactions with NUMB and Deltex homologs, which are important cytosolic factors that regulate the Notch pathway. Downregulation of Notch signaling requires phosphorylation of NICD on a C-terminal proline, glutamic acid, serine and threonine (PEST) domain, and further modification by E3 ubiquitin ligases, such as F-box/WD repeat-containing protein 7 (FBW7), which promote proteasomal degradation of NICD. In the absence of NICD, RBP-J is associated with co-repressor (Co-R) proteins and histone deacetylases (HDACs), which act to repress the transcription of target 


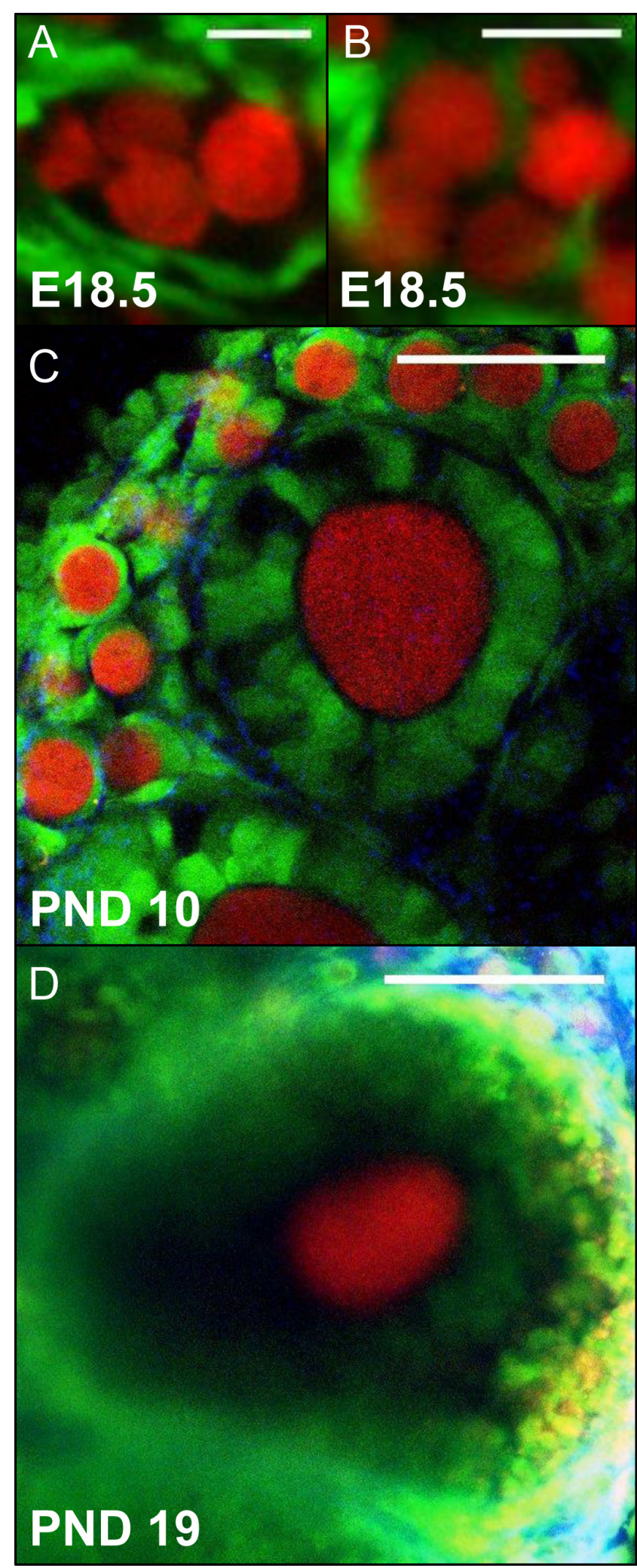

Figure 2 Notch activity during follicle assembly, growth, and maturation. A Notch-responsive GFP reporter mouse line, used to label Notch active cells (green), was crossed with a Vasa-Cre mouse and conditional tdTomato reporter line, to label germ cells (red). (A) Notch active pregranulosa cells surround clusters of germ cells in genes; thus, activation of the Notch pathway involves a switch from a repressed state to an activated state.

Emerging evidence also indicates that the Notch pathway can be regulated through several noncanonical mechanisms (D'Souza et al. 2010, Heitzler 2010, Andersen et al. 2012). These include activation by membrane ligands such as delta-like 1 homolog (DLK1) (Baladron et al. 2005) and delta- and notchlike epidermal growth factor-related receptor (DNER) (Eiraku et al. 2005), GPI-linked ligands including F3/contactin 1 (CNTN1) (Hu et al. 2003) and NB3/ contactin 6 (CNTN6) (Cui et al. 2004) and secreted ligands such as connective tissue growth factor/ cysteine-rich 61/nephroblastoma overexpressed gene 3 (CCN3) (Sakamoto et al. 2002), microfibril-associated glycoprotein family 1 (MAGP1) and 2 (MAGP2) (Miyamoto et al. 2006), thrombospondin 2 (TSP2) (Meng et al. 2009), Y-box protein 1 (YB1) (Rauen et al. 2009) and EGF-like domain 7 (EGFL7) (Schmidt et al. 2009). Some of these ligands impact Notch signaling by functioning as activators or inhibitors in either trans or cis, and some of them can also regulate Notch activation independent of $\gamma$-secretase proteolysis by causing dissociation of the Notch receptor heterodimer, as with MAGP2, or by facilitating interactions with other downstream modulators at the cell surface, including Deltex and $\beta$-Arrestin (Mukherjee et al. 2005). Importantly, many of the observations regarding noncanonical Notch signaling have yet to be proven within in vivo systems; thus, the significance of these findings is still unknown, and non-canonical signaling has not been well-studied within the ovary.

\section{Notch pathway in the developing ovary}

During embryonic ovarian development, Notch receptors, ligands and target genes are expressed (Table 1). NOTCH2, which is localized to somatic pregranulosa cells, is the most abundantly expressed receptor within the embryonic ovary, while the Notch ligands JAG1 and JAG2, which are found in the germ cells of the embryonic ovary, are the most abundantly expressed ligands (Vanorny et al. 2014). The use of a summative Notch-responsive fluorescent reporter mouse line demonstrates that activation of the Notch pathway in the embryonic ovary is first observed

an embryonic day 18.5 (E18.5) ovary (scale bar=20 microns). (B) Notch active cells can also be seen invading germ cell syncytia and sending projections around individual germ cells to form primordial follicles (scale bar $=20$ microns). (C) Notch active pregranulosa cells are observed within primordial follicles at the ovarian cortex of a postnatal day 8 (PND8) ovary, while granulosa cells within primary follicles demonstrate variable Notch reporter activity. Collagen fibrils (blue) were detected by second harmonic generation (scale bar $=50$ microns). (D) Within antral follicles, both cumulus and mural granulosa cells are Notch active (scale bar $=100$ microns). 
around embryonic day 15.5 (E15.5) and is restricted to somatic cells (Vanorny et al. 2014). Furthermore, Notch activation within the embryonic mouse ovary is concomitant with a significant increase in the expression of the ligands, Jag1 and Jag2, the receptor, Notch2, and the Notch target genes Hes1 and Hey2 (Vanorny et al. 2014). At E18.5, Notch active pregranulosa cells can be observed undergoing dramatic reorganization to form an intricate network around ovigerous cords containing partially fragmented germ cell nests (Fig. 2A and B). Additionally, Notch active pregranulosa cells, which are organized along collagen fibrils, begin to invade nests and can be seen sending cellular projections around and encapsulating individual germ cells to form primordial follicles (Vanorny et al. 2014). With these data, a model begins to emerge in which upregulation of Jag 1 and Jag2 in the oocyte, signals through Notch2 expressed in pregranulosa cells to facilitate the resolution of germ cell syncytia and assembly of primordial follicles.

Functional studies in embryonic ovaries demonstrate that the Notch pathway is important for germ cell syncytia formation and meiotic entry. The inhibition of
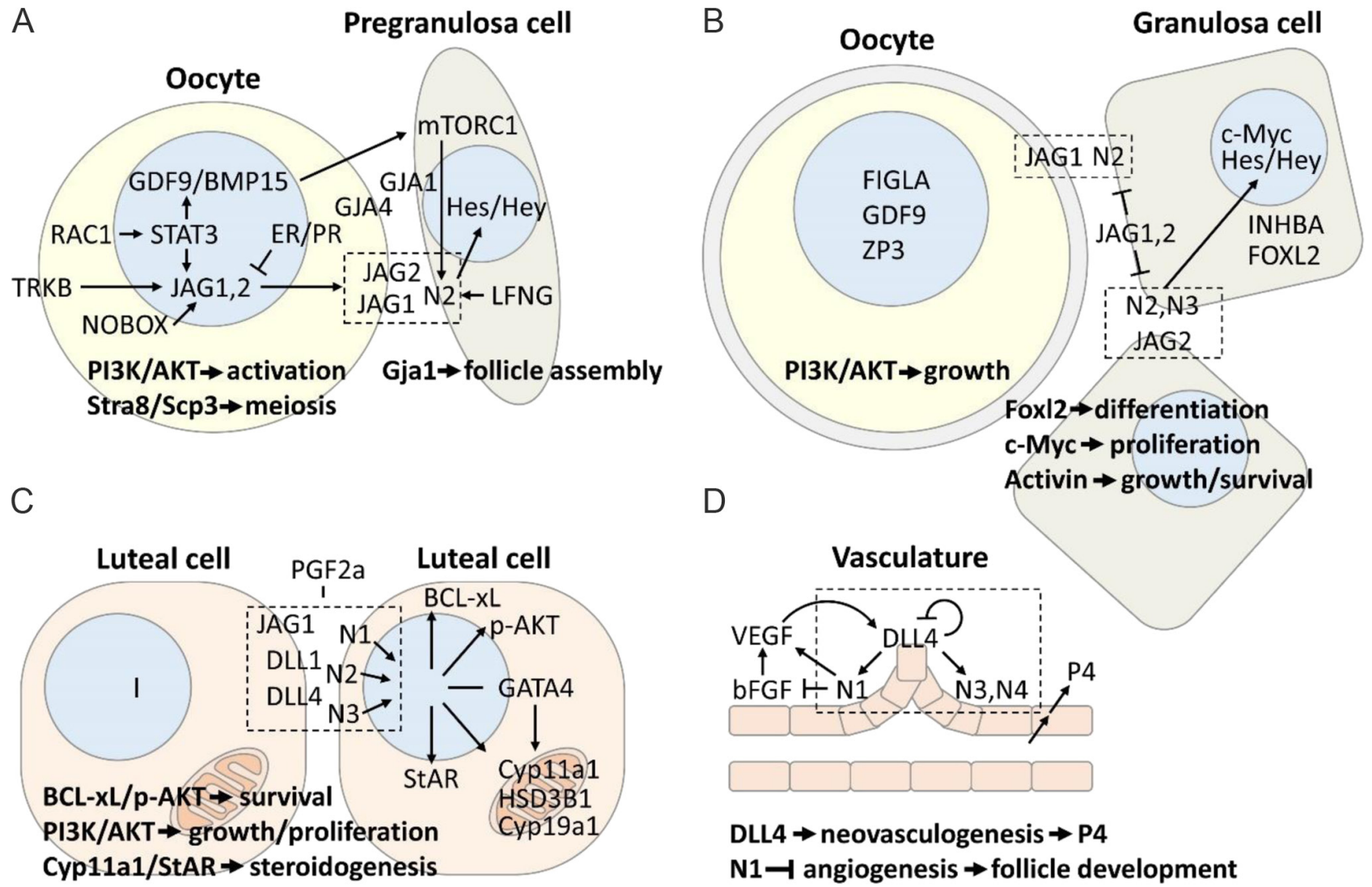

Figure 3 Regulation and function of Notch signaling during ovarian and follicle development. The Notch pathway has multiple roles during follicle assembly and growth, steroidogenesis and ovarian vascular development. (A) Bidirectional communication between germ cells and somatic support cells is critical for follicle assembly. In the mammalian ovary, this process appears to be regulated in large part by the modulation of Jag1, and possibly Jag2, transcription in germ cells, which is regulated by NOBOX, STAT3, TRKB and steroid hormone action. Upregulation of Notch ligand expression in oocytes facilitates interactions with adjacent pregranulosa cells expressing Notch receptor that is supported by growth factors (i.e., GDF9 and BMP15) from the oocyte. Notch signaling between germ cells and somatic pregranulosa cells promotes follicle assembly and has non-cell autonomous roles on oocyte development including the regulation of meiosis and oocyte activation. (B) Notch signaling supports follicular growth and maturation by regulating granulosa cell differentiation, proliferation, and survival. Formation of zona pellucida in oocytes may impede productive Notch signaling between oocytes and granulosa cells; thus, within multi-laminar follicles, continued trans-activing interactions between Notch receptors and ligands likely occur between juxtaposed granulosa cells. The expression of Notch receptors and ligands in these granulosa cells therefore, must facilitate both bidirectional inductive signaling yet overcome cis-inhibition due to receptor-ligand co-expression. Functionally, continued Notch signaling in growing follicles promotes Fox/2 expression, activin action, and has non-cell autonomous effects on oocyte growth and maturation. (C) Steroid production in luteal cells is modulated by Notch signaling through transcriptional regulation of enzymes involved in steroid biosynthesis. Bidirectional inductive signaling and cisinhibitory mechanisms likely coordinate these processes. Notch signaling also functions to prevent luteolysis by regulating the expression of the anti-apoptotic factor BCL-xL and the pro-survival factor p-AKT. (D) Notch signaling, mediated predominately through the actions of Notch 1, 3 and 4, regulates bFGF-induced VEGF-mediated angiogenesis and the differentiation and activity of endothelial tips cells that express DLL4. These events modulate neovascularization and vascular density to support follicle growth and progesterone (P4) production. (A, B and C) The schematic representations of cells used in these figures were spatially separated for clarity. 
Notch signaling in embryonic ovarian explants using the pharmacological $\gamma$-secretase inhibitor $\mathrm{N}$-[N-(3,5difluorophenacetyl)-L-alanyl]-S-phenylglycine t-butyl ester (DAPT) results in the suppression of retinoic acid induced stimulation of Stra8 expression and a reduction in downstream targets deleted in azoospermia-like $($ Dazl), disrupted meiotic cDNA protein 1 (Dmc1) and meiotic recombination protein 8 (Rec8) (Feng et al. 2014). Furthermore, siRNA knockdown of Notch 1 leads to markedly reduced expression of both Stra8 and synaptonemal complex protein 3 (Scp3) (Fig. 3A). Reduction in Stra8 expression following Notch inhibition is correlated with increased methylation of the Stra8 proximal promoter region, suggesting that Notch signaling regulates the epigenetic status of the Stra8 promoter. These changes cause delayed meiotic progression, defective oocyte growth and aberrant primordial follicle assembly resulting in the formation of multi-oocytic follicles within renal grafts of embryonic ovarian tissue exposed to $\gamma$-secretase inhibitors (Feng et al. 2014), consistent with a relationship between meiotic progression and follicle assembly.

Pharmacological inhibition of Notch signaling with the $\gamma$-secretase inhibitors DAPT and L-685,458 in neonatal ovaries using an ex vivo ovary culture system results in delayed syncytial breakdown (Trombly et al. 2009b, Chen et al. 2014), fewer primordial follicles (Trombly et al. 2009b, Chen et al. 2014), decreased granulosa cell proliferation (Terauchi et al. 2016), increased numbers of degenerative oocytes (Terauchi et al. 2016), and decreased expression of the germ cell markers newborn ovary homeobox protein (Nobox), factor in the germline alpha (Fig/a), LIM/ homeobox protein 8 (Lhx 8$)$, and spermatogenesis and oogenesis specific basic helix-loop-helix 1 (Soh/h2) (Chen et al. 2014). Interestingly, the deletion of Nobox in mice causes markedly delayed syncytial breakdown, accelerated postnatal oocyte loss and decreased ovarian expression of Jag1 (Fig. 3A) (Rajkovic et al. 2004), while Figla null mice display aberrant follicle assembly and postnatal oocyte loss due to the failure of pregranulosa cells to associate properly with germ cells (Soyal et al. 2000). The disruption of Notch signaling using DAPT is also associated with decreased recruitment of granulosa precursors and aberrant follicle assembly, which is similar to the phenotype observed with pharmacological inhibition or conditional knockout of the cell surface sheddase Adam 10 (Feng et al. 2016). In addition, RNAimediated knockdown of Jag2 or Notch1 also leads to disrupted follicle assembly in cultured ovarian explants (Guo et al. 2012).

Multiple observations suggest that maternally-derived steroid hormones are important for the maintenance of germ cell syncytia in the ovaries of fetal rodents, and that the subsequent loss of exposure to these hormones at the time of birth leads to the initiation of follicle histogenesis. Additionally, treatment with estrogens (Iguchi et al. 1990, Chen et al. 2007, 2009) or progestins (Iguchi et al. 2001, Nilsson et al. 2006) leads to an increased incidence of multi-oocytic follicles. Progesterone has also been shown to directly disrupt follicle histogenesis (Iguchi 1992, Kezele \& Skinner 2003, Chen et al. 2007) and result in the suppression of Jag2, Notch1 and Hey2 expression in both in vivo and in vitro systems (Guo et al. 2012). Surprisingly, the treatment of neonatal ovaries with the progesterone antagonist RU486 also leads to the suppression of Jag2, Notch1 and Hey2 expression (Guo et al. 2012), suggesting that an appropriate steroid hormone environment is required for the accurate regulation of Notch components. Despite cross-talk between steroid hormone signaling and the Notch pathway, the formation of multi-oocytic follicles in models of altered steroid hormone action may have distinct etiologies from those resulting from disrupted Notch signaling. Unlike treatment with DES, exposure of neonatal ovaries to DAPT does not result in increased numbers of multi-oocytic follicles when examined histologically after renal grafting (Terauchi et al. 2016). This is in contrast to similar studies that did report the formation of multi-oocytic follicles following treatment with DAPT using embryonic ovaries (Feng et al. 2014). These findings indicate that alternative mechanisms or windows of sensitivity may exist in which DES exposure or Notch inhibition can cause perturbations to follicle assembly.

\section{Genetic models of Notch pathway disruption in the ovary}

Given that Notch1 and Notch4 expression is largely restricted to the ovarian vasculature (Table 1 ), and that mice with global deletion of Notch3 (Krebs et al. 2003), Notch4 (Krebs et al. 2000) or both Notch3 and Notch4 (Xu 2011) have no overt reproductive phenotype, the expression of Notch2 in granulosa cells has the greatest potential to mediate the actions of Notch signaling during follicle assembly and growth. Moreover, JAG1 has been shown to productively interact with $\mathrm{NOTCH} 2$ (Shimizu et al. 1999, 2000a,b); thus, it is hypothesized that JAG1, and possibly JAG2, expressed in germ cells of perinatal ovaries signals through $\mathrm{NOTCH} 2$ expressed in granulosa cells to facilitate germ and somatic cell interactions that are important for follicle formation and development. However, importantly, since global deletion of either Jag1 or Notch2 results in embryonic lethality (Xue et al. 1999, McCright et al. 2006), tissuespecific approaches are required to investigate the role of these genes within the developing ovary.

Conditional deletion of the Notch ligand, Jag1, in germ cells (J1KO) (Vanorny et al. 2014) or the Notch receptor, Notch2, in somatic pregranulosa cells (N2KO) (Xu \& Gridley 2013, Vanorny et al. 2014) produces a phenotype characterized by decreased numbers of 


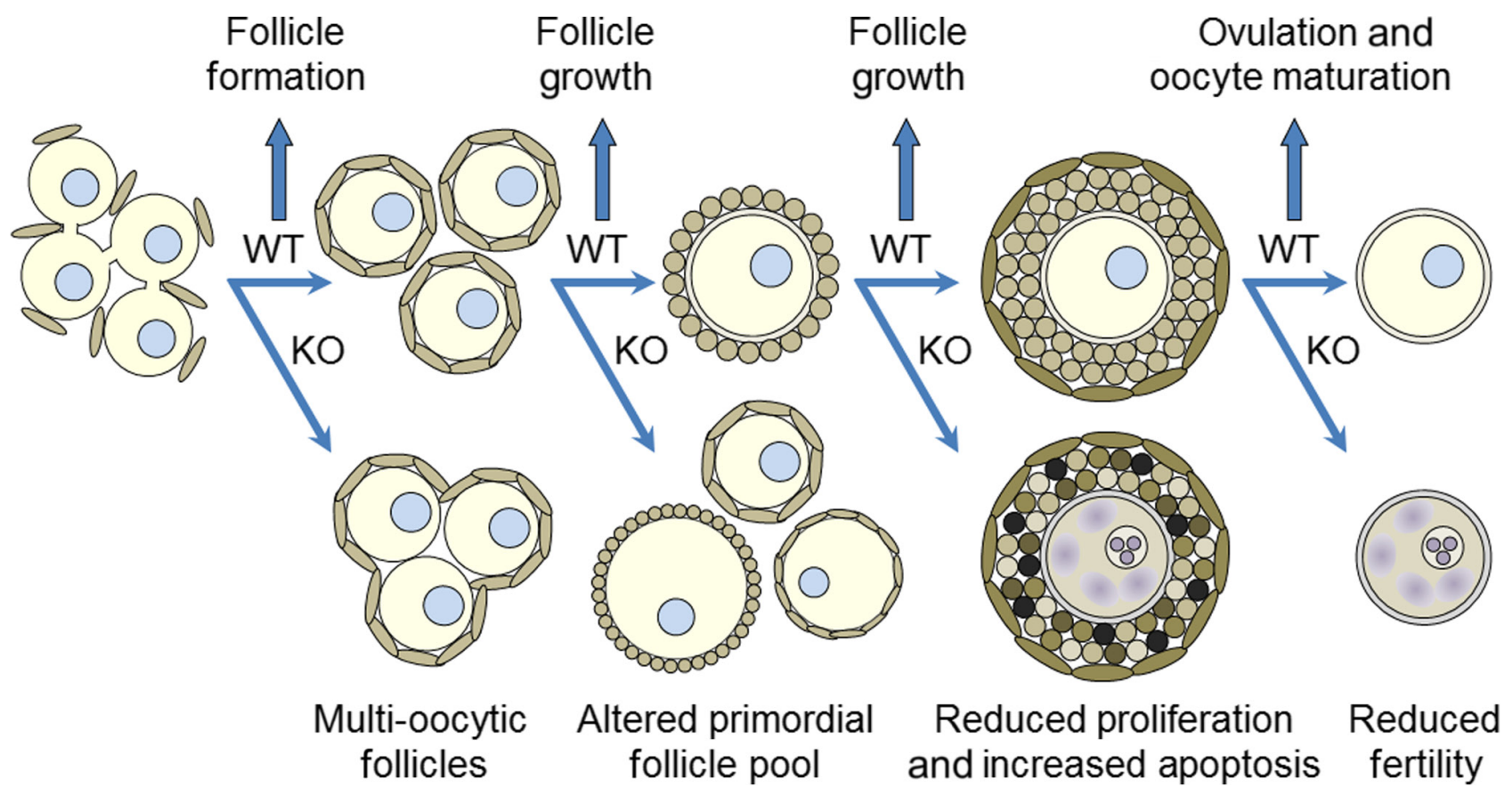

Figure 4 Summary of observed phenotypes in Notch pathway knockout mice during ovarian follicle development. Disruption of Notch signaling between oocytes and somatic pregranulosa cells, as observed in $\mathrm{J} 1 \mathrm{KO}$ and $\mathrm{N} 2 \mathrm{KO}$ mice, leads to perturbations in follicle assembly characterized by the presence of multi-oocytic follicles, which represent a failure to completely resolve germ cell syncytia. Loss of Notch signaling also leads to changes in follicle dynamics that adversely impact the primordial follicle pool and development of antral follicles, which is accompanied by decreased proliferation and increased apoptosis of granulosa cells. As a consequence of these defects, female Notch knockout mice are subfertile. These mouse models demonstrate important functions for Notch signaling in the resolution of germ cell syncytia, coordination of somatic and germ cell growth within follicles, and oocyte maturation.

primordial follicles, persistence of germ cell syncytia at the ovarian cortex, uncoordinated follicle growth and aberrant folliculogenesis (Fig. 4). The most striking feature of these genetic models is the presence of numerous multi-oocytic follicles, which is evidence of significantly disturbed ovigerous cord fragmentation or syncytial breakdown. Interestingly, in the Drosophila ovariole, disruption of the ligand Delta in the germ line, the receptor Notch in follicle cells or the Lfng homolog, Fringe in somatic polar cells, results in the production of fused and enlarged egg chambers containing multiple oocytes (Grammont \& Irvine 2001, Torres et al. 2003), suggesting functional conservation of Notch signaling across metazoan ovarian development.

In postnatal day 1 (PND1) N2KO ovaries, decreased germ and pregranulosa cell apoptosis is observed ( $\mathrm{Xu}$ \& Gridley 2013), possibly due to delayed syncytial breakdown, which is a process that normally results in massive germ cell loss. In contrast, at PND19, there is a significant increase in somatic cell apoptosis and a decrease in granulosa cell proliferation within growing follicles of both $\mathrm{J} 1 \mathrm{KO}$ and $\mathrm{N} 2 \mathrm{KO}$ ovaries (Fig. 4) (Vanorny et al. 2014). Both knockout models also contain follicles in which there is oocyte expansion in the absence of granulosa cell growth, which is consistent with a role for Notch signaling in somatic cell proliferation and maturation. N2KO ovaries also contain increased numbers of atretic follicles and follicles that become cystic, hemorrhagic and contain trapped oocytes (Xu \& Gridley 2013), similar to mouse genetic models of disturbed estrogen (Couse \& Korach 1999, Britt et al. 2000), activin (McMullen et al. 2001, BristolGould et al. 2005, Pangas et al. 2007) and gonadotropin signaling (Risma et al. 1995, 1997, Kumar et al. 1999, Keri et al. 2000, Matzuk et al. 2003, Meehan et al. 2005). In addition, both conditional knockout models contain reduced numbers of antral follicles, while J1KO ovaries also contain fewer corpora lutea, consistent with the reduction in ovarian follicle growth and ovulation capacity (Vanorny et al. 2014).

Interestingly, the transcript levels of Notch2 are elevated in J1KO ovaries, and conversely, the levels of Jag1 are elevated in $\mathrm{N} 2 \mathrm{KO}$ ovaries, signifying a mechanism of compensatory expression between lag1 and Notch2 (Vanorny et al. 2014). In addition, the expression of Jag2 and Notch 1 are increased in J1KO ovaries. These data indicate that the effects of Jag 1 or Notch 2 deletion might be masked through compensation or functional complementation by the expression of other Notch ligands or receptors. Transcript levels of growth differentiation factor 9 (Gdf9), zona pellucida glycoprotein $3(Z p 3)$ and Figla are elevated in both J1 KO and $\mathrm{N} 2 \mathrm{KO}$ ovaries, consistent with the observation of follicles with uncoordinated growth between the oocyte 
and somatic layer (Fig. 3B). Additionally, within J1KO ovaries, the expression of inhibin beta A (Inhba) and B $(I n h b b)$ is decreased, consistent with the phenotype of altered granulosa cell proliferation and decreased ovarian reserve respectively (Fig. 3B).

Histological examination of ovaries in which Jag1 and Notch 2 are both deleted in the germ and somatic cell compartments reveals that the effect of combined deletion of Jag 1 and Notch2 produces an ovarian phenotype similar to the conditional deletion of either gene individually (Vanorny et al. 2014). This finding is consistent with a model in which Jag1 in germ cells directly signals through Notch2 in granulosa cells. As a consequence of the multiple defects resulting from disrupted Notch signaling between germ cells and granulosa cells, both J1KO (Vanorny et al. 2014) and N2KO (Xu \& Gridley 2013) models display reduced fertility, as measured by a reduction in litter size and total progeny, and some female $\mathrm{J} 1 \mathrm{KO}$ and $\mathrm{N} 2 \mathrm{KO}$ mice appear to undergo premature reproductive senescence (Vanorny et al. 2014). Furthermore, preliminary studies suggest that the impaired fertility observed in J1KO females may result from a combination of reduced oocyte quality and a trend toward reduced ovulatory capacity, whereas N2KO females have reduced oocyte quality, but preserved ovulatory potential (Vanorny 2016).

Constitutive expression of Notch1 intracellular domain (NICD1) through induction with Amhr2Cre leads to multiple abnormalities within the female reproductive tract of mice (Manosalva et al. 2013, Ferguson et al. 2016). Importantly, NICD1 has been shown to fully complement the actions of the Notch2 intracellular domain (NICD2) (Liu et al. 2015); thus, the overexpression of NICD1 is functionally equivalent to constitutive activation of Notch2. The predominant ovarian phenotype displayed in these animals includes the presence of hemorrhagic blood vessels and cystic lesions (Ferguson et al. 2016), and an increased number of mature oocytes and a decreased number of pregranulosa cells (Manosalva et al. 2013). Importantly, these mice have significant extra-ovarian pathologies consisting of aberrant coiling and canalization of the oviducts, and the presence of hemorrhagic blood vessels and cystic lesions in the uteri and oviducts. These features, which are fully penetrant in older females (Ferguson et al. 2016), are similar to the phenotypes observed in mouse models with disruption of Wnt family members 4 (Wnt4) and 7a (Wnt7a), $\beta$-catenin and Dicer (Vainio et al. 1999, Nagaraja et al. 2008, Hernandez Gifford et al. 2009). Although gain-of-function NICD1 female mice are subfertile (Manosalva et al. 2013, Ferguson et al. 2016), follicular development appears to be largely normal in these mice (Ferguson et al. 2016), suggesting that the altered fertility observed in these animals is possibly extra-ovarian in origin.

Ovaries from traditional or conditional Hes 1 knockout mice contain germ cells with decreased cellular diameters and fewer total germ cells, similar to those treated with DAPT, due to increased apoptosis resulting from the failure to suppress the pro-apoptotic gene Inhbb (Manosalva et al. 2013). In addition, Hes 1 knockout ovaries contain germ cells with reduced markers of oocyte maturity, as measured by the expression of Kit, which has been shown to promote primordial follicle activation and survival of late-stage follicles (Hutt et al. 2006). Interestingly, despite the presence of fewer germ cells, there are increased numbers of pregranulosa cells in Hes 1 knockouts, which is correlated with increased levels of forkhead box protein L2 (Fox/2) and follistatin (Fst) expression (Manosalva et al. 2013). Notably, in either Hes 1 conditional or global knockouts, female mice are subfertile; thus, suppression of the Notch effector gene within granulosa cells leads to impaired follicular function that impacts female fertility.

Disruption of the fucose-specific glycosyltransferase Lfng leads to complete infertility in a large subset of female mice that survive into adulthood (Hahn et al. 2005), although some survivors can have productive matings (Xu et al. 2006). Mutation of Lfng is also associated with abnormal folliculogenesis characterized by the presence of multi-oocytic follicles and follicles with disorganized thecal layers. Unexpectedly, given the poor fertility of Lfng knockouts, follicles of all developmental stages are present within mutant ovaries at roughly equivalent numbers and percentages in comparison to controls (Hahn et al. 2005). Additionally, corpora lutea are observed in Lfng null ovaries, indicating that mutant mice are capable of cycling and ovulating naturally; however, many of the corpora lutea contain trapped oocytes indicative of defective ovulation. Interestingly, despite altered folliculogenesis and diminished fertility, no difference is observed in the number of oocytes ovulated following gonadotropin stimulation. Analysis of ovulated oocytes however demonstrates significantly impaired meiotic maturation resulting in the failure of oocytes to complete meiosis due to aberrant meiotic spindle assembly (Hahn et al. 2005). Notably, ovarian expression of both Jag 1 and Notch2 is reduced in Lfng null mice, and mutant ovaries share many of the phenotypic features observed in J1 KO and $\mathrm{N} 2 \mathrm{KO}$ ovaries.

\section{Regulation of Notch pathway expression and action during follicle development}

Suppression of Notch signaling in ex vivo cultured ovarian explants using the $\gamma$-secretase inhibitors DAPT or L-685,458 results in the presence of fewer primordial follicles and delayed follicle recruitment, culminating in fewer growing and total follicles (Wang et al. 2014). This reduction in total follicle numbers is associated with decreased granulosa cell proliferation, increased germ cell apoptosis and decreased expression of 
germ cell-specific transcription factors. Interestingly, Notch inhibition appears to be coupled with increased expression of PTEN, suggesting that suppression of Notch signaling in pregranulosa cells may disrupt follicle development by preventing PI3K/AKT mediated germ cell activation (Fig. 3A), consistent with studies demonstrating a role of pregranulosa cells in primordial follicle activation (Zhang \& Liu 2015).

Secondary ovarian follicles cultured in a Notch suppressive environment with the $\gamma$-secretase inhibitors DAPT and L-685, 458 have been shown to display arrested growth, exhibit granulosa cell detachment and contain degenerative oocytes (Zhang et al. 2011). Furthermore, $\gamma$-secretase inhibitor treatment leads to a reduction in granulosa cell proliferation that is concomitant with decreased $c-M y c$ expression. Surprisingly, gainof-function experiments using lentiviral-mediated expression of NICD2 within cultured granulosa cells show a restoration of $c-M y c$ expression and rescue of granulosa cell proliferation in the presence of DAPT (Zhang et al. 2011). This demonstrates that the Notch effector c-Myc plays a critical role in the maintenance and function of granulosa cells.

Ovarian follicles require the formation of gap junctions through the expression of gap junction protein alpha 1 (Gja1) in granulosa cells and gap junction protein alpha 4 (Gja4) in oocytes to prevent premature meiotic resumption (Simon et al. 1997, Juneja et al. 1999). Pharmacological disruption of gap junction complexes in cultured ovarian explants leads to a marked decrease in the expression of Notch2 in pregranulosa cells resulting in reduced somatic cell proliferation (Teng et al. 2016). In addition, germ cells remain in syncytial structures and fail to appropriately assemble into follicular units. Inhibition of Notch signaling using DAPT results in a reciprocal decrease in the expression of multiple gap junction proteins and the key granulosa cell transcription factor Fox/2, supporting an important and complementary relationship between productive Notch signaling and gap junction formation that is required for primordial follicle formation and maintenance (Fig. 3A).

The small GTPase, Rac1, has been shown to play an indispensable role in primordial follicle formation by controlling nuclear import of STAT3 in germ cells, which facilitates the transcription of the Notch ligand, Jag1, and the expression of Gdf9, bone morphogenetic protein 15 (Bmp15) and Nobox (Fig. 3A) (Zhao et al. 2016). Increased expression of the oocyte-specific growth factors leads to increased translation of $\mathrm{NOTCH} 2$ in granulosa cells, via mammalian target of rapamycin complex 1 (mTORC1) modulation (Fig. 3A), which is subsequently activated by juxtaposed germ cells expressing JAG1. Similar to models of suppressed Notch signaling, disruption of Rac1 action through pharmacological inhibition or siRNA knockdown leads to delayed syncytial breakdown, reduced numbers of primordial follicles and increased numbers of multioocytic follicles. Conversely, overexpression of Jag1 in oocytes rescues Rac1 inhibition and leads to accelerated syncytial breakdown and follicle assembly through the activation of Notch2 in juxtaposed pregranulosa cells.

The tyrosine kinase receptor tropomyosin-related kinase receptor B $(\operatorname{TrkB})$, which supports the actions of neurotropin 4/5 (Nt-4) and brain-derived neurotrophic factor $(B d n f)$ during folliculogenesis, has also been shown to impact Notch signaling within the developing ovary (Dorfman et al. 2011). Similar to Rac1, TrkB expression within the ovary is specific to germ cells where it is suspected of being a direct regulator of Jag1 transcription (Fig. 3A). In addition to Jag1, the expression of Hes 1 and Hey 2 are reduced in TrkB null ovaries, suggesting that the inability to express Jag 1 within the oocyte leads to suppressed Notch signaling within adjacent granulosa cells expressing Notch2. The deletion of $\operatorname{Trk} B$ also leads to a reduction in granulosa cell proliferation, delayed follicular growth and reduced ovarian follicle survival, consistent with findings from other reports of disrupted Notch signaling within the ovary and studies using blocking antibodies against BDNF and NT-4 (Spears et al. 2003). Interestingly, lentiviral-mediated expression of Jag 1 targeted to germ cells of TrkB null ovaries restores Notch activation and rescues the expression of the downstream Notch effector c-Myc (Fig. 3B). Notably, although lacking in TrkB null ovaries, mice with disruption of the neurotrophin nerve growth factor (Ngf) exhibit multi-oocytic follicles in addition to reduced numbers of primary and secondary follicles (Dissen et al. 2001).

Once formed, primordial follicles remain quiescent until select cohorts are recruited each reproductive cycle when they undergo a transition from primordial to primary follicles. This process, termed follicle activation, results in morphological and physiological changes in both the oocyte and somatic cells. Oocytes within activated follicles begin to grow, while squamous pregranulosa cells transition into cuboidal granulosa cells, become proliferative, and later steroidogenic and responsive to pituitary gonadotropins. Within this growing pool of follicles, components of the Notch pathway are dynamically expressed (Table 1) (Johnson et al. 2001, Hahn et al. 2005, Trombly et al. 2009a, Vanorny et al. 2014). The ligand Jag2 and the receptors Notch2 and Notch 3 are localized to granulosa cells, the ligand Jag 1 is found in oocytes, and the target genes Hes 1 and Hey 2 are expressed in granulosa cells. Interestingly, Hes 1 is localized to both somatic and germ cells of embryonic and postnatal ovaries (Trombly et al. 2009b, Zhang et al. 2011, Manosalva et al. 2013), suggesting an important bidirectional role for the Notch pathway during folliculogenesis. However, the deletion of $R b p$-j in oocytes under the direction of TNAP-Cre does not have any impact on follicle development or fertility (Manosalva et al. 2013), confirming that canonical 
Notch activity within the oocyte is dispensable for normal ovarian function and that the actions of Notch signaling are mediated through its function in somatic cell types.

Within a developing follicle, physical contact between the inner layer of granulosa cells and oocyte is maintained via the formation of transzonal projections (TZPs), which are thin cellular extensions that emanate from granulosa cells and penetrate the zona pellucida ( $\mathrm{Li}$ \& Albertini 2013). However, as granulosa cells proliferate to form multi-laminar follicles, they consequently lose direct contact with the oocyte, which may preclude continued juxtacrine signaling between the two cell types. Accordingly, continued Notch activation within the granulosa cells of developing follicles requires the interactions of juxtaposed granulosa cells. Examination of a Notch fluorescent reporter demonstrates continued, though variable, Notch activity within granulosa cells of secondary follicles (Fig. 2C) and within both mural and cumulus granulosa cells of antral follicles (Fig. 2D) that persists through ovulation and luteinization (Vanorny et al. 2014, Vanorny 2016). It is interesting to consider whether a change in the source of Notch ligand during this transition may play a role in follicle activation and in the new cellular processes acquired by granulosa cells.

Change in the source of ligand used for continued Notch activation following follicle recruitment also requires the conversion from Jag1, in oocytes, to Jag2, in granulosa cells. Although the specific role of Jag2 in the ovary has not been determined, a naturally occurring hypomorphic allele for Jag2 reportedly has poor female fertility (Gruneberg 1956), signifying that this ligand may be critical for ovarian function. Additionally, the expression pattern of Jag2 resembles that of the Notch ligand Delta, which is expressed in the germline cells and later in somatic follicle cells of Drosophila ovarioles (Lopez-Schier \& St Johnston 2001, Torres et al. 2003), again suggesting an evolutionarily conserved role for Notch signaling in metazoan follicle development.

\section{Notch signaling during luteinization}

Following stimulation by pituitary gonadotropins, granulosa and thecal cells that remain within follicles that ovulate undergo luteinization to form corpora lutea, which provide a source of steroid hormones throughout pregnancy. The Notch ligands Jag1, D/l1 and D//4 and the Notch receptors Notch1-4 have all been shown to be expressed within small and large luteal cells (Table 1) Johnson et al. 2001, Vorontchikhina et al. 2005, Hernandez et al. 2011, Murta et al. 2014, Accialini et al. 2015, Wang et al. 2015), consistent with a role for Notch signaling in their function. Following in vivo treatment with prostaglandin F2 alpha (PGF2a), a uterine-derived factor that initiates luteolysis in rodents, transcripts for
Notch1, Notch4 and D/l4 are reduced, as are cleaved forms of the receptors (Fig. 3C) (Hernandez et al. 2011). Additionally, the suppression of Notch signaling through intrabursal injection with DAPT leads to decreased progesterone production and increased luteal cell apoptosis. These findings suggest that the luteolytic effects of PGF2a may be in part an effect of decreased Notch activation, which is consistent with a luteotropic role for Notch signaling.

Treatment of cultured mouse luteal cells with DAPT or L-658,458 results in a reduction in both basal and hCGinduced progesterone production (Wang et al. 2015). In addition, the inhibitory effects on progesterone levels observed in luteal cells treated with DAPT have been shown to arise from the suppression of cytochrome P450 family 11 subfamily A member 1 (Cyp 11a1) expression. In contrast, overexpression of the intracellular domain of Notch3 (NICD3) causes an increase in both basal and hCG-induced progesterone secretion through the regulation of Cyp11a1 and steroidogenic acute regulatory protein $(S t A R)$, which controls the ratelimiting step in steroid biosynthesis (Fig. 3C). These results indicate that the activation of Notch signaling and stimulation with hCG have synergistic effects on progesterone production in luteal cells. Interestingly, overexpression of NICD3 has no observable effect on estrogen levels despite the regulation of upstream enzymes in the steroid synthesis pathway.

Mechanically isolated rat corpora lutea cultured in the presence of DAPT also have decreased levels of progesterone production as a consequence of the reduced expression of Cyp11a1 (Accialini et al. 2015). Furthermore, suppression of Notch signaling is able to reverse progesterone-induced expression of StAR. Consistent with in vivo studies, cultured corpora lutea treated with DAPT have increased markers of apoptosis, as a consequence of decreased levels of the antiapoptotic protein $\mathrm{BCL}-\mathrm{xL}$ and the pro-survival factor phosphorylated AKT (Fig. 3C). Moreover, suppression of Notch activation is able to reverse the survival effects that progesterone has on luteal cells. Similar to treatments with DAPT, corpora lutea incubated with an inactivating DLL4 antibody have decreased progesterone production. These findings support a novel role for the Notch pathway in the regulation of luteal function in response to progesterone stimulation, and indicate an important relationship between the actions of progesterone and Notch signaling.

In contrast to the findings above, transfection of a gonadotropin-responsive mouse cell line with NICD1 or NICD2 leads to a decrease in progesterone production, implying that Notch activation normally functions to suppress steroidogenesis (George et al. 2015). In addition, the expression of StAR, Cyp 19a 1 and HSD3b1 are significantly upregulated following pharmacological suppression of Notch signaling in cultured preantral follicles and downregulated with transient transfection 
of NICD1-3. Furthermore, the activation of the Notch pathway represses the ability of GATA4 to induce the expression of these genes through Notch target gene expression and promoter binding, rather than through dimerization of Notch target genes with GATA4 (Fig. 3C) (George et al. 2015). These findings, together with studies employing DLL4 and $\gamma$-secretase inhibitors discussed above, indicate that alteration in the levels of basal Notch activity negatively impact progesterone production in steroidogenically active cells, suggesting complex regulatory effects of steroid hormone production by Notch signaling.

\section{Notch pathway in the ovarian vasculature}

The Notch pathway has previously been shown to be critical for multiple aspects of vasculogenesis and angiogenesis including arteriovenous specification, endothelial and vascular smooth muscle cell differentiation, and the regulation of vessel sprouting and branching (Fig. 3D and Table 1) (Krebs et al. 2000, Gridley 2007, 2010). Several Notch components are expressed within the ovarian vasculature including D/l4 located at the tip of endothelial cells within the thecal layer (Jovanovic et al. 2013) and growing luteal vessels (Garcia-Pascual et al. 2013); Notch3 within endothelial cells and vascular smooth muscle cells (Jovanovic et al. 2013); and Notch1, Notch4 and Jag1 within thecal layer endothelial and vascular smooth muscle cells (Vorontchikhina et al. 2005, Jovanovic et al. 2013).

The Notch ligand, D//4, is primarily localized to vascular endothelial cells where it acts to regulate the differentiation and activity of tips cells, which are located at the growing edge of the ovarian neovasculature. The treatment of marmosets during the periovulatory period with a neutralizing DLL4 antibody demonstrates that D/l4 acts as a negative regulator of vascular endothelial growth factor (VEGF)-mediated sprouting and branching within the ovarian vasculature (Fig. 3D) (Fraser et al. 2012). In addition, the inhibition of D/l4 induces luteal hypervascularization, including increased angiogenesis and vascular density, which is associated with a decrease in progesterone production. Furthermore, primate ovaries in which D/l4 is perturbed are reduced in size and weight, and corpora lutea undergo enhanced degeneration due to increased cellular apoptosis. Interestingly, the inhibition of D/l4 during the midluteal phase has only a minimal impact on progesterone production and does not affect follicular development.

In immature female mice treated with PMSG and hCG, to stimulate follicle development, injection of an inhibitory DLL4 antibody promotes promiscuous expression of D/l4 leading to increased, but nonfunctional, vascularization that is associated with decreased progesterone production (Fig. 3D) (GarciaPascual et al. 2013). In contrast, suppression of Notch signaling using a pan-Notch inhibitor, compound E ( $\quad(\mathrm{s}, \mathrm{s})-[2-(3,5-D i f l u o r o p h e n y)$-acetylamino]- $\mathrm{N}-(1-$ methyl-2-oxo-5-phenyl-2,3-dihydro-1H-benzo[e] [1,4] diazepin-3-yl)-propionamide), causes a reduction in ovarian weight and estrogen production as a result of uninhibited, but highly disorganized, vascular proliferation that culminates in blocked follicle development at the preovulatory stage (Jovanovic et al. 2013). Thus, while the blockade of Notch signaling using a DLL4 inhibitory antibody has an effect on the organization of the follicular vasculature, it appears to have little or no impact on gonadotropin-dependent folliculogenesis, suggesting the involvement of other Notch ligands in this process. These studies demonstrate a specific role for D/l4 in suppressing vascular overgrowth and in organizing ovarian neovasculature during luteal formation.

The role of Notch signaling within the ovarian vasculature of mice has also been examined using a gainof-function genetic model (Liu et al. 2014). Constitutive activation of the Notch pathway in vascular endothelial cells by the induction of NICD1 expression under the control of a tamoxifen-inducible Tie2-Cre allele results in severely altered female fertility, and ovaries from these mice lack mature ovarian follicles. The specific mechanism behind the interrupted development of advanced follicles is attributed to the inhibition of bFGFinduced angiogenesis (Fig. 3D), supporting a critical role for Notch signaling in vascular development during ovarian follicle maturation.

\section{Role of Notch signaling in the human ovary}

Transcriptional profiling of human preantral follicles demonstrates that Notch components are expressed and dynamically regulated during follicle growth in humans (Kristensen et al. 2015). Abundantly expressed Notch pathway transcripts in human preantral follicles include Jag1, Hes 1 and Hey2, whereas low to moderately expressed transcripts include Notch1, Notch2, Notch3, Jag2 and Hes5. Notch signaling components with no discernable expression in human preantral follicles include Notch4, D/l1, DII3, D//4 and Hes7. Additionally, the expression of the Notch target gene Hey 1 is significantly reduced with increasing preantral follicle size. In human cumulus granulosa cells obtained by follicle aspiration during IVF, all four Notch receptors and the Notch ligands JAG1 and JAG2 are expressed (Tanriverdi et al. 2013). When comparing poor and normal responders to IVF treatments, there is a significant reduction in the expression of $\mathrm{NOTCH} 2$ in the cumulus cells of the poor responders and the expression of both $\mathrm{NOTCH} 2$ and $\mathrm{NOTCH} 3$ are positively correlated with IVF response.

Polycystic ovarian syndrome (PCOS) is the most common endocrine disorder in females of reproductive 
age and is characterized by hyperandrogenism, insulin resistance, chronic anovulation and infertility (Fauser et al. 2012). Ovarian follicles in PCOS patients frequently exhibit arrest of follicle growth at the antral stage leading to the appearance of ovaries containing multiple cysts on diagnostic imaging studies. In addition, there is a reduction in granulosa cell proliferation, hyperplasia of the theca interna, and disrupted ovulation. Profiling of miRNA transcripts in women with PCOS demonstrates that Notch3 is a target of miRNAs that are differentially expressed in the cumulus cells of these patients (Xu et al. 2015). The miRNA hsa-miR-483-5p has been specifically shown to regulate the expression of both Notch3 and mitogen-activated protein kinase (Mapk), suggesting that women with PCOS may have alterations in granulosa cell proliferation and function in part through decreased Notch action.

Each year more than 20,000 women in the United States are diagnosed with, and approximately 14,000 die from, ovarian cancer, making it the leading cause of death from gynecologic malignancy (Group 2014). The overall five-year survival rate for ovarian cancer is approximately $31 \%$ (Jemal et al. 2009), and this high rate of mortality can be largely explained by the frequent occurrence of patients with an advanced-stage of disease at the time of diagnosis (Koonings et al. 1989). Notably, genomic profiling has revealed that as many as $22 \%$ of high-grade serous ovarian carcinomas contain mutations in components of the Notch pathway with more than $50 \%$ of those cases involving Notch 3 (Cancer Genome Atlas Research Network 2011), which is highly associated with poor clinical outcomes (Hu et al. 2014). In addition, the Notch ligands Jag1 (Choi et al. 2008, Cancer Genome Atlas Research Network 2011) and Jag2 (Euer et al. 2005, Cancer Genome Atlas Research Network 2011) are also commonly amplified in these cancers, resulting in enhanced Notch signaling, likely through a Notch3 juxtacrine loop, which supports ovarian tumor growth and cellular adhesion (Choi et al. 2008). Though Notch3 is the receptor most frequently involved in ovarian carcinogenesis, the activity of Notch 1 has also been shown to be elevated in a subset of these cancers (Rose et al. 2010).

Alterations in the expression of Notch pathway genes has also been correlated with ovarian cancers that develop resistance to treatment (Groeneweg et al. 2014); however, it is unclear by what means aberrant Notch signaling may facilitate the survival of cancer cells. Difficulty in treating ovarian tumors has at least in part been attributed to the formation or maintenance of cancer stem cells (Jordan et al. 2006, Shah et al. 2013, Walters Haygood et al. 2014). Stem cell factors such as Nanog and Oct4 have been shown to be upregulated by the overexpression of NICD3 in cells of the ovarian surface epithelium, suggesting a potential role in supporting an undifferentiated cellular state (Park et al. 2010). In addition, aberrant Notch signaling may cause the loss of an epithelial phenotype through an epithelial to mesenchymal transition; thus, allowing tumor cells to acquire a stem cell-like phenotype and resistance to certain therapies (Espinoza \& Miele 2013).

Notch signaling has also been shown to play important roles in tumor angiogenesis of other cancers (Li et al. 2007, Benedito et al. 2009), though only a few studies have specifically examined an angiogenic role in ovarian cancer. In one report, Jag 1 was shown to be upregulated in ovarian tumor epithelial cells, and disruption of the gene led to a reduction in blood vessel formation and endothelial migration (Lu et al. 2007). In a second study (Hu et al. 2011), D/l4 was found to be upregulated in more than half of the ovarian cancer samples that were analyzed, and increased levels of D//4 expression were correlated with overall poor survival. New treatments designed to target the Notch pathway will hopefully provide additional means to counter the various mechanisms by which altered Notch signaling promotes the establishment and maintenance of tumors, especially those that are resistant to current therapeutic options (Rose 2009, Domingo-Domenech et al. 2012, Sahebjam et al. 2013, Groeneweg et al. 2014).

\section{Conclusions}

The Notch pathway supports juxtacrine signaling between families of membrane-bound ligands and receptors, and plays a fundamental role in numerous cellular processes during metazoan development. Notch signaling is active in the embryonic mouse ovary and is strongly upregulated at birth in somatic cells that surround germ cell syncytia, coincident with the resolution of these syncytia and establishment of the primordial follicle pool. Communication between juxtaposed germ cells and somatic support cells of the ovary is critical for the formation of follicles and for the establishment of the follicular niche in which the oocyte will develop through ovulation. In addition, the Notch pathway promotes the growth and maturation of ovarian follicles through interactions with juxtaposed follicular cells. Cellular interactions between other populations of cell types within the developing ovary also facilitate productive Notch signaling that is critical for ovarian processes including luteinization and vascular development, which are central to the production and delivery of critical secreted hormonal factors that support pregnancy and female health.

The phenotypes observed in models of disrupted Notch signaling are consistent with the broad functions ascribed to Notch signaling in the regulation of cellular processes that include proliferation, cell death or survival, adhesion and migration, and differentiation and cell-fate specification. These diverse roles for Notch signaling are highly context-dependent and consistent with the concept that the ovary and its functional unit, 
the follicle, represent a highly complex and dynamic continuum of developmental stages. To address the pathophysiology underlying the considerable histological derangements observed in ovaries with disrupted Notch signaling, additional studies are needed to identify new genes and interactions with other signaling pathways involved in the downstream regulatory actions of the Notch pathway. Furthermore, new strategies to culture and visualize ovarian tissues should help to elucidate the dynamic cellular behaviors and relationships involved in the coordination of ovarian and follicle development.

This review and emerging evidence indicates that the Notch pathway is critical for the establishment of a microenvironment where the female germ cell develops and has distinct regulatory roles throughout the development of the ovarian follicle to support female reproductive function. Understanding the juxtacrine signaling mechanisms by which ovarian follicles serve as a critical environmental niche for the maturation of female germ cells is vital for addressing human infertility and for establishing new reproductive technologies to improve oocyte quality and preserve reproductive function and fertility. Furthermore, examination of the interplay between multiple signaling modalities within the ovary and reproductive axis should allow for a greater recognition of essential signaling and regulatory networks for the development of new therapeutic paradigms for the improvement of women's health.

\section{Declaration of interest}

The authors declare that there is no conflict of interest that could be perceived as prejudicing the impartiality of this review.

\section{Funding}

The original research reported in this review was supported by a grant from the Eunice Kennedy Shriver National Institute of Child Health and Human Development (P01 HD021921) to K E M. D A V received support from the Cellular and Molecular Basis of Disease Training Program through a grant from the National Institutes of Health, Institute of General Medical Sciences (T32 GM08061). The Northwestern University Multi-Photon Core received support through a grant from the National Institute of Neurological Disorders and Stroke (P30 NS054850).

\section{Acknowledgements}

The authors would like to thank Dr Pamela Monahan, Rexxi Prasasya and Nisan Hubbard for their critical evaluation of this review.

\section{References}

Accialini P, Hernandez SF, Bas D, Pazos MC, Irusta G, Abramovich D \& Tesone M 2015 A link between Notch and progesterone maintains the functionality of the rat corpus luteum. Reproduction 149 1-10. (doi:10.1530/REP-14-0449)

Albertini DF, Combelles CM, Benecchi E \& Carabatsos MJ 2001 Cellular basis for paracrine regulation of ovarian follicle development. Reproduction 121 647-653. (doi:10.1530/rep.0.1210647)

Andersen P, Uosaki H, Shenje LT \& Kwon C 2012 Non-canonical Notch signaling: emerging role and mechanism. Trends in Cell Biology 22 257-265. (doi:10.1016/j.tcb.2012.02.003)

Anderson EL, Baltus AE, Roepers-Gajadien HL, Hassold TJ, de Rooij DG, van Pelt AM \& Page DC 2008 Stra8 and its inducer, retinoic acid, regulate meiotic initiation in both spermatogenesis and oogenesis in mice. PNAS 105 14976-14980. (doi:10.1073/pnas.0807297105)

Andersson ER, Sandberg R \& Lendahl U 2011 Notch signaling: simplicity in design, versatility in function. Development 138 3593-3612. (doi:10.1242/dev.063610)

Artavanis-Tsakonas S, Rand MD \& Lake RJ 1999 Notch signaling: cell fate control and signal integration in development. Science 284 770-776. (doi:10.1126/science.284.5415.770)

Baladron V, Ruiz-Hidalgo MJ, Nueda ML, Diaz-Guerra MJ, GarciaRamirez JJ, Bonvini E, Gubina E \& Laborda J 2005 dlk acts as a negative regulator of Notch1 activation through interactions with specific EGFlike repeats. Experimental Cell Research 303 343-359. (doi:10.1016/j. yexcr.2004.10.001)

Benedito R, Roca C, Sorensen I, Adams S, Gossler A, Fruttiger M \& Adams RH 2009 The notch ligands Dll4 and Jagged1 have opposing effects on angiogenesis. Cell 137 1124-1135. (doi:10.1016/j.cell.2009.03.025)

Blaumueller CM, Qi H, Zagouras P \& Artavanis-Tsakonas S 1997 Intracellular cleavage of Notch leads to a heterodimeric receptor on the plasma membrane. Cell 90 281-291. (doi:10.1016/S00928674(00)80336-0)

Bristol-Gould SK, Hutten CG, Sturgis C, Kilen SM, Mayo KE \& WoodruffTK 2005 The development of a mouse model of ovarian endosalpingiosis. Endocrinology 146 5228-5236. (doi:10.1210/en.2005-0697)

Britt KL, Drummond AE, Cox VA, Dyson M, Wreford NG, Jones ME, Simpson ER \& Findlay JK 2000 An age-related ovarian phenotype in mice with targeted disruption of the Cyp 19 (aromatase) gene. Endocrinology 141 2614-2623. (doi:10.1210/en.141.7.2614)

Bulman MP, Kusumi K, Frayling TM, McKeown C, Garrett C, Lander ES, Krumlauf R, Hattersley AT, Ellard S \& Turnpenny PD 2000 Mutations in the human delta homologue, DLL3, cause axial skeletal defects in spondylocostal dysostosis. Nature Genetics 24 438-441. (doi:10.1038/74307)

Cancer Genome Atlas Research Network 2011 Integrated genomic analyses of ovarian carcinoma. Nature 474 609-615. (doi:10.1038/ nature10166)

Chau MD, Tuft R, Fogarty K \& Bao ZZ 2006 Notch signaling plays a key role in cardiac cell differentiation. Mechanisms of Development $\mathbf{1 2 3}$ 626-640. (doi:10.1016/j.mod.2006.06.003)

Chen Y, Jefferson WN, Newbold RR, Padilla-Banks E \& Pepling ME 2007 Estradiol, progesterone, and genistein inhibit oocyte nest breakdown and primordial follicle assembly in the neonatal mouse ovary in vitro and in vivo. Endocrinology 148 3580-3590. (doi:10.1210/en.2007-0088)

Chen Y, Breen K \& Pepling ME 2009 Estrogen can signal through multiple pathways to regulate oocyte cyst breakdown and primordial follicle assembly in the neonatal mouse ovary. Journal of Endocrinology 202 407-417. (doi:10.1677/JOE-09-0109)

Chen CL, Fu XF, Wang LQ, Wang JJ, Ma HG, Cheng SF, Hou ZM, Ma JM, Quan GB, Shen W \& Li L 2014 Primordial follicle assembly was regulated by Notch signaling pathway in the mice. Molecular Biology Reports 41 1891-1899. (doi:10.1007/s11033-014-3038-4)

Choi JH, Park JT, Davidson B, Morin PJ, Shih le M \& Wang TL 2008 Jagged-1 and Notch3 juxtacrine loop regulates ovarian tumor growth and adhesion. Cancer Research 68 5716-5723. (doi:10.1158/00085472.CAN-08-0001)

Conti M, Hsieh M, Zamah AM \& Oh JS 2012 Novel signaling mechanisms in the ovary during oocyte maturation and ovulation. Molecular and Cellular Endocrinology 356 65-73. (doi:10.1016/j.mce.2011.11.002) 
Couse JF \& Korach KS 1999 Estrogen receptor null mice: what have we learned and where will they lead us? Endocrine Reviews 20 358-417. (doi:10.1210/edrv.20.3.0370)

Cui XY, Hu QD, Tekaya M, Shimoda Y, Ang BT, Nie DY, Sun L, Hu WP, Karsak M, Duka T et al. 2004 NB-3/Notch1 pathway via Deltex1 promotes neural progenitor cell differentiation into oligodendrocytes. Journal of Biological Chemistry 279 25858-25865. (doi:10.1074/jbc. M313505200)

D'Souza B, Meloty-Kapella L \& Weinmaster G 2010 Canonical and noncanonical Notch ligands. Current Topics in Developmental Biology 92 73-129. (doi:10.1016/s0070-2153(10)92003-6)

Dissen GA, Romero C, Hirshfield AN \& Ojeda SR 2001 Nerve growth factor is required for early follicular development in the mammalian ovary. Endocrinology 142 2078-2086. (doi:10.1210/en.142.5.2078)

Doetzlhofer A, Basch ML, Ohyama T, Gessler M, Groves AK \& Segil N 2009 Hey2 regulation by FGF provides a Notch-independent mechanism for maintaining pillar cell fate in the organ of Corti. Developmental Cell 16 58-69. (doi:10.1016/j.devcel.2008.11.008)

Domingo-Domenech J, Vidal SJ, Rodriguez-Bravo V, Castillo-Martin M, Quinn SA, Rodriguez-Barrueco R, Bonal DM, Charytonowicz E, Gladoun N, de la Iglesia-Vicente J et al. 2012 Suppression of acquired docetaxel resistance in prostate cancer through depletion of notch- and hedgehog-dependent tumor-initiating cells. Cancer Cell 22 373-388. (doi:10.1016/j.ccr.2012.07.016)

Dorfman MD, Kerr B, Garcia-Rudaz C, Paredes AH, Dissen GA \& Ojeda SR 2011 Neurotrophins acting via TRKB receptors activate the JAGGED1-NOTCH2 cell-cell communication pathway to facilitate early ovarian development. Endocrinology 152 5005-5016. (doi:10.1210/ en.2011-1465)

Edson MA, Nagaraja AK \& Matzuk MM 2009 The mammalian ovary from genesis to revelation. Endocrine Reviews 30 624-712. (doi:10.1210/ er.2009-0012)

Ehebauer M, Hayward P \& Martinez-Arias A 2006 Notch signaling pathway. Science's STKE 2006 cm7. (doi:10.1126/stke.3642006cm7)

Eiraku M, Tohgo A, Ono K, Kaneko M, Fujishima K, Hirano T \& Kengaku M 2005 DNER acts as a neuron-specific Notch ligand during Bergmann glial development. Nature Neuroscience 8 873-880. (doi:10.1038/ nn1492)

Espinoza I \& Miele L 2013 Deadly crosstalk: Notch signaling at the intersection of EMT and cancer stem cells. Cancer Letters 341 41-45. (doi:10.1016/j.canlet.2013.08.027)

Euer NI, Kaul S, Deissler H, Mobus VJ, Zeillinger R \& Weidle UH 2005 Identification of L1CAM, Jagged2 and Neuromedin $U$ as ovarian cancerassociated antigens. Oncology Reports 13 375-387. (doi:10.3892/ or.13.3.375)

Fauser BC, Tarlatzis BC, Rebar RW, Legro RS, Balen AH, Lobo R, Carmina E, Chang J, Yildiz BO, Laven JS et al. 2012 Consensus on women's health aspects of polycystic ovary syndrome (PCOS): the Amsterdam ESHRE/ ASRM-Sponsored 3rd PCOS Consensus Workshop Group. Fertility and Sterility 97 28.e25-38.e25. (doi:10.1016/j.fertnstert.2011.09.024)

Feng YM, Liang GJ, Pan B, Qin XS, Zhang XF, Chen CL, Li L, Cheng SF, De Felici M \& Shen W 2014 Notch pathway regulates female germ cell meiosis progression and early oogenesis events in fetal mouse. Cell Cycle 13 782-791. (doi:10.4161/cc.27708)

Feng L, Wang Y, Cai H, Sun G, Niu W, Xin Q, Tang X, Zhang J, Wang C, Zhang $\mathbf{H}$ et al. 2016 ADAM10-Notch signaling governs the recruitment of ovarian pregranulosa cells and controls folliculogenesis in mice. Journal of Cell Science 129 2202-2212. (doi:10.1242/jcs.184267)

Ferguson L, Kaftanovskaya EM, Manresa C, Barbara AM, Poppiti RJ, Tan Y \& Agoulnik Al 2016 Constitutive Notch signaling causes abnormal development of the oviducts, abnormal angiogenesis, and cyst formation in mouse female reproductive tract. Biology of Reproduction 9467. (doi:10.1095/biolreprod.115.134569)

Flores GV, Duan H, Yan H, Nagaraj R, Fu W, Zou Y, Noll M \& Banerjee U 2000 Combinatorial signaling in the specification of unique cell fates. Cell 103 75-85. (doi:10.1016/S0092-8674(00)00106-9)

Fortini ME 2002 Gamma-secretase-mediated proteolysis in cell-surfacereceptor signalling. Nature Reviews Molecular Cell Biology 3 673-684. (doi:10.1038/nrm910)

Fraser HM, Hastings JM, Allan D, Morris KD, Rudge JS \& Wiegand SJ 2012 Inhibition of delta-like ligand 4 induces luteal hypervascularization followed by functional and structural luteolysis in the primate ovary. Endocrinology 153 1972-1983. (doi:10.1210/en.2011-1688)

Garcia TX \& Hofmann MC 2013 NOTCH signaling in Sertoli cells regulates gonocyte fate. Cell Cycle 12 2538-2545. (doi:10.4161/cc.25627)

Garcia-Pascual CM, Zimmermann RC, Ferrero H, Shawber CJ, Kitajewski J, Simon C, Pellicer A \& Gomez R 2013 Delta-like ligand 4 regulates vascular endothelial growth factor receptor 2-driven luteal angiogenesis through induction of a tip/stalk phenotype in proliferating endothelial cells. Fertility and Sterility 100 1768.e1761-1776.e1761. (doi:10.1016/j. fertnstert.2013.08.034)

Garg V, Muth AN, Ransom JF, Schluterman MK, Barnes R, King IN, Grossfeld PD \& Srivastava D 2005 Mutations in NOTCH1 cause aortic valve disease. Nature 437 270-274. (doi:10.1038/nature03940)

George RM, Hahn KL, Rawls A, Viger RS \& Wilson-Rawls J 2015 Notch signaling represses GATA4-induced expression of genes involved in steroid biosynthesis. Reproduction 150 383-394. (doi:10.1530/REP-150226)

Gordon WR, Vardar-Ulu D, L'Heureux S, Ashworth T, Malecki MJ, Sanchez-Irizarry C, McArthur DG, Histen G, Mitchell JL, Aster JC et al. 2009 Effects of S1 cleavage on the structure, surface export, and signaling activity of human Notch1 and Notch2. PLoS ONE 4 e6613. (doi:10.1371/journal.pone.0006613)

Grammont M \& Irvine KD 2001 fringe and Notch specify polar cell fate during Drosophila oogenesis. Development 128 2243-2253.

Greenwald I \& Kovall R 2013 Notch signaling: genetics and structure. WormBook 1-28. (doi:10.1895/wormbook.1.10.2)

Gridley T 2003 Notch signaling and inherited disease syndromes. Human Molecular Genetics 12 R9-R13. (doi:10.1093/hmg/ddg052)

Gridley T 2007 Notch signaling in vascular development and physiology. Development 134 2709-2718. (doi:10.1242/dev.004184)

Gridley T 2010 Notch signaling in the vasculature. Current Topics in Developmental Biology 92 277-309. (doi:10.1016/s00702153(10)92009-7)

Groeneweg JW, Foster R, Growdon WB, Verheijen RH \& Rueda BR 2014 Notch signaling in serous ovarian cancer. Journal of Ovarian Research 7 95. (doi:10.1186/s13048-014-0095-1)

Group UCSW 2014 United States Cancer Statistics: 1999-2011 Incidence and Mortality Web-Based Report. Atlanta, GA, USA: Department of Health and Human Services, Centers for Disease Control and Prevention, and National Cancer Institute.

Gruneberg H 1956 Genetical studies on the skeleton of the mouse. XVIII. Three genes for syndactylism. Journal of Genetics 54 113-145. (doi:10.1007/BF02981706)

Guo M, Zhang H, Bian F, Li G, Mu X, Wen J, Mao G, Teng Z, Xia G \& Zhang M 2012 P4 down-regulates Jagged2 and Notch1 expression during primordial folliculogenesis. Frontiers in Bioscience (Elite Edition) 4 2731-2744. (doi:10.2741/E579)

Hahn KL, Johnson J, Beres BJ, Howard S \& Wilson-Rawls J 2005 Lunatic fringe null female mice are infertile due to defects in meiotic maturation. Development 132 817-828. (doi:10.1242/dev.01601)

Haines N \& Irvine KD 2003 Glycosylation regulates Notch signalling. Nature Reviews Molecular Cell Biology 4 786-797. (doi:10.1038/nrm1228)

Hayashi H \& Kume T 2008 Foxc transcription factors directly regulate Dll4 and Hey2 expression by interacting with the VEGF-Notch signaling pathways in endothelial cells. PLOS ONE 3 e2401. (doi:10.1371/journal. pone.0002401)

Heitzler P 2010 Biodiversity and noncanonical Notch signaling. Current Topics in Developmental Biology 92 457-481. (doi:10.1016/s00702153(10)92014-0)

Hernandez F, Peluffo MC, Stouffer RL, Irusta G \& Tesone M 2011 Role of the DLL4-NOTCH system in PGF2alpha-induced luteolysis in the pregnant rat. Biology of Reproduction 84 859-865. (doi:10.1095/ biolreprod.110.088708)

Hernandez Gifford JA, Hunzicker-Dunn ME \& Nilson JH 2009 Conditional deletion of beta-catenin mediated by Amhr2cre in mice causes female infertility. Biology of Reproduction 80 1282-1292. (doi:10.1095/ biolreprod.108.072280)

Hu QD, Ang BT, Karsak M, Hu WP, Cui XY, Duka T, Takeda Y, Chia W, Sankar N, Ng YK et al. 2003 F3/contactin acts as a functional ligand for Notch during oligodendrocyte maturation. Cell 115 163-175. (doi:10.1016/S0092-8674(03)00810-9) 
Hu W, Lu C, Dong HH, Huang J, Shen DY, Stone RL, Nick AM, Shahzad MM, Mora E, Jennings NB et al. 2011 Biological roles of the Delta family Notch ligand Dll4 in tumor and endothelial cells in ovarian cancer. Cancer Research 71 6030-6039. (doi:10.1158/0008-5472.CAN-102719)

Hu W, Liu T, Ivan C, Sun Y, Huang J, Mangala LS, Miyake T, Dalton HJ, Pradeep S, Rupaimoole R et al. 2014 Notch3 pathway alterations in ovarian cancer. Cancer Research 74 3282-3293. (doi:10.1158/00085472.CAN-13-2066)

Huang Z, Rivas B \& Agoulnik Al 2013 NOTCH1 gain of function in germ cells causes failure of spermatogenesis in male mice. PLOS ONE 8 e71213. (doi:10.1371/journal.pone.0071213)

Hutt KJ, McLaughlin EA \& Holland MK 2006 KIT/KIT ligand in mammalian oogenesis and folliculogenesis: roles in rabbit and murine ovarian follicle activation and oocyte growth. Biology of Reproduction 75 421-433. (doi:10.1095/biolreprod.106.051516)

Iguchi T 1992 Cellular effects of early exposure to sex hormones and antihormones. International Review of Cytology 139 1-57. (doi:10.1016/ s0074-7696(08)61409-6)

Iguchi T, Fukazawa Y, Uesugi Y \& Takasugi N 1990 Polyovular follicles in mouse ovaries exposed neonatally to diethylstilbestrol in vivo and in vitro. Biology of Reproduction 43 478-484. (doi:10.1095/biolreprod43.3.478)

Iguchi T, Watanabe H \& Katsu Y 2001 Developmental effects of estrogenic agents on mice, fish, and frogs: a mini-review. Hormones and Behavior 40 248-251. (doi:10.1006/hbeh.2001.1675)

Jemal A, Siegel R, Ward E, Hao Y, Xu J \& Thun MJ 2009 Cancer statistics, 2009. CA: A Cancer Journal for Clinicians 59 225-249. (doi:10.3322/ caac.20006)

Johnson J, Espinoza T, McGaughey RW, Rawls A \& Wilson-Rawls J 2001 Notch pathway genes are expressed in mammalian ovarian follicles. Mechanisms of Development 109 355-361. (doi:10.1016/S09254773(01)00523-8)

Jordan KC, Clegg NJ, Blasi JA, Morimoto AM, Sen J, Stein D, McNeill H, Deng WM, Tworoger M \& Ruohola-Baker H 2000 The homeobox gene mirror links EGF signalling to embryonic dorso-ventral axis formation through notch activation. Nature Genetics 24 429-433. (doi:10.1038/74294)

Jordan CT, Guzman ML \& Noble M 2006 Cancer stem cells. New England Journal of Medicine 355 1253-1261. (doi:10.1056/NEJMra061808)

Joutel A, Corpechot C, Ducros A, Vahedi K, Chabriat H, Mouton P, Alamowitch S, Domenga V, Cecillion $\mathrm{M}$, Marechal $\mathrm{E}$ et al. 1996 Notch3 mutations in CADASIL, a hereditary adult-onset condition causing stroke and dementia. Nature 383 707-710. (doi:10.1038/383707a0)

Jovanovic VP, Sauer CM, Shawber CJ, Gomez R, Wang X, Sauer MV, Kitajewski J \& Zimmermann RC 2013 Intraovarian regulation of gonadotropin-dependent folliculogenesis depends on notch receptor signaling pathways not involving Delta-like ligand 4 (DII4). Reproductive Biology and Endocrinology 11 43. (doi:10.1186/1477-7827-11-43)

Juneja SC, Barr KJ, Enders GC \& Kidder GM 1999 Defects in the germ line and gonads of mice lacking connexin43. Biology of Reproduction $\mathbf{6 0}$ 1263-1270. (doi:10.1095/biolreprod60.5.1263)

Keri RA, Lozada KL, Abdul-Karim FW, Nadeau JH \& Nilson JH 2000 Luteinizing hormone induction of ovarian tumors: oligogenic differences between mouse strains dictates tumor disposition. PNAS 97 383-387. (doi:10.1073/pnas.97.1.383)

Kezele P \& Skinner MK 2003 Regulation of ovarian primordial follicle assembly and development by estrogen and progesterone: endocrine model of follicle assembly. Endocrinology 144 3329-3337. (doi:10.1210/ en.2002-0131)

Knight PG \& Glister C 2006 TGF-beta superfamily members and ovarian follicle development. Reproduction 132 191-206. (doi:10.1530/ rep.1.01074)

Kolev V, Mandinova A, Guinea-Viniegra J, Hu B, Lefort K, Lambertini C, Neel V, Dummer R, Wagner EF \& Dotto GP 2008 EGFR signalling as a negative regulator of Notch1 gene transcription and function in proliferating keratinocytes and cancer. Nature Cell Biology 10 902-911. (doi:10.1038/ncb1750)

Koonings PP, Campbell K, Mishell DR Jr \& Grimes DA 1989 Relative frequency of primary ovarian neoplasms: a 10-year review. Obstetrics and Gynecology 74 921-926. (doi:10.1016/0020-7292(90)90378-X)
Kopan R 2002 Notch: a membrane-bound transcription factor. Journal of Cell Science 115 1095-1097.

Kopan R \& Goate A 2000 A common enzyme connects notch signaling and Alzheimer's disease. Genes and Development 14 2799-2806. (doi:10.1101/gad.836900)

Koubova J, Menke DB, Zhou Q, Capel B, Griswold MD \& Page DC 2006 Retinoic acid regulates sex-specific timing of meiotic initiation in mice. PNAS 103 2474-2479. (doi:10.1073/pnas.0510813103)

Krebs LT, Xue Y, Norton CR, Shutter JR, Maguire M, Sundberg JP, Gallahan D, Closson V, Kitajewski J, Callahan R et al. 2000 Notch signaling is essential for vascular morphogenesis in mice. Genes and Development 14 1343-1352. (doi:10.1101/gad.14.11.1343)

Krebs LT, Xue Y, Norton CR, Sundberg JP, Beatus P, Lendahl U, Joutel A \& Gridley T 2003 Characterization of Notch3-deficient mice: normal embryonic development and absence of genetic interactions with a Notch1 mutation. Genesis 37 139-143. (doi:10.1002/gene.10241)

Kristensen SG, Ebbesen P \& Andersen CY 2015 Transcriptional profiling of five isolated size-matched stages of human preantral follicles. Molecular and Cellular Endocrinology 401 189-201. (doi:10.1016/j. mce.2014.12.012)

Kumar TR, Palapattu G, Wang P, WoodruffTK, Boime I, Byrne MC \& Matzuk MM 1999 Transgenic models to study gonadotropin function: the role of follicle-stimulating hormone in gonadal growth and tumorigenesis. Molecular Endocrinology 13 851-865. (doi:10.1210/mend.13.6.0297)

Leong KG \& Karsan A 2006 Recent insights into the role of Notch signaling in tumorigenesis. Blood 107 2223-2233. (doi:10.1182/ blood-2005-08-3329)

Li R \& Albertini DF 2013 The road to maturation: somatic cell interaction and self-organization of the mammalian oocyte. Nature Reviews Molecular Cell Biology 14 141-152. (doi:10.1038/nrm3531)

Li L, Milner LA, Deng Y, Iwata M, Banta A, Graf L, Marcovina S, Friedman C, Trask BJ, Hood L et al. 1998 The human homolog of rat Jagged1 expressed by marrow stroma inhibits differentiation of $32 \mathrm{D}$ cells through interaction with Notch1. Immunity 8 43-55. (doi:10.1016/S10747613(00)80457-4)

Li JL, Sainson RC, Shi W, Leek R, Harrington LS, Preusser M, Biswas S, Turley H, Heikamp E, Hainfellner JA et al. 2007 Delta-like 4 Notch ligand regulates tumor angiogenesis, improves tumor vascular function, and promotes tumor growth in vivo. Cancer Research 67 11244-11253. (doi:10.1158/0008-5472.CAN-07-0969)

Lindsell CE, Boulter J, diSibio G, Gossler A \& Weinmaster G 1996 Expression patterns of Jagged, Delta1, Notch1, Notch2, and Notch3 genes identify ligand-receptor pairs that may function in neural development. Molecular and Cellular Neuroscience 8 14-27. (doi:10.1006/mcne.1996.0040)

Liu J, Deutsch U, Jeong J \& Lobe CG 2014 Constitutive notch signaling in adult transgenic mice inhibits bFGF-induced angiogenesis and blocks ovarian follicle development. Genesis 52 809-816. (doi:10.1002/ dvg.22790)

Liu Z, Brunskill E, Varnum-Finney B, Zhang C, Zhang A, Jay PY, Bernstein I, Morimoto M \& Kopan R 2015 The intracellular domains of Notch1 and Notch2 are functionally equivalent during development and carcinogenesis. Development 142 2452-2463. (doi:10.1242/ dev.125492)

Logeat F, Bessia C, Brou C, LeBail O, Jarriault S, Seidah NG \& Israel A 1998 The Notch1 receptor is cleaved constitutively by a furin-like convertase. PNAS 95 8108-8112. (doi:10.1073/pnas.95.14.8108)

Lopez-Schier H \& St Johnston D 2001 Delta signaling from the germ line controls the proliferation and differentiation of the somatic follicle cells during Drosophila oogenesis. Genes and Development 15 1393-1405. (doi:10.1101/gad.200901)

Lu C, Bonome T, Li Y, Kamat AA, Han LY, Schmandt R, Coleman RL, Gershenson DM, Jaffe RB, Birrer MJ \& Sood AK 2007 Gene alterations identified by expression profiling in tumor-associated endothelial cells from invasive ovarian carcinoma. Cancer Research 67 1757-1768. (doi:10.1158/0008-5472.CAN-06-3700)

Lubman OY, llagan MX, Kopan R \& Barrick D 2007 Quantitative dissection of the Notch:CSL interaction: insights into the Notch-mediated transcriptional switch. Journal of Molecular Biology 365 577-589. (doi:10.1016/j.jmb.2006.09.071)

Maillard I \& Pear WS 2003 Notch and cancer: best to avoid the ups and downs. Cancer Cell 3 203-205. (doi:10.1016/S1535-6108(03)00052-7) 
Manosalva I, Gonzalez A \& Kageyama R 2013 Hes1 in the somatic cells of the murine ovary is necessary for oocyte survival and maturation. Developmental Biology 375 140-151. (doi:10.1016/j. ydbio.2012.12.015)

Matzuk MM, DeMayo FJ, Hadsell LA \& Kumar TR 2003 Overexpression of human chorionic gonadotropin causes multiple reproductive defects in transgenic mice. Biology of Reproduction 69 338-346. (doi:10.1095/ biolreprod.102.013953)

McCright B, Lozier J \& Gridley T 2006 Generation of new Notch2 mutant alleles. Genesis 44 29-33. (doi:10.1002/gene.20181)

McLaren A 1984 Meiosis and differentiation of mouse germ cells. Symposia of the Society for Experimental Biology 38 7-23.

McMullen ML, Cho BN, Yates CJ \& Mayo KE 2001 Gonadal pathologies in transgenic mice expressing the rat inhibin alpha-subunit. Endocrinology 142 5005-5014. (doi:10.1210/en.142.11.5005)

Meehan TP, Harmon BG, Overcast ME, Yu KK, Camper SA, Puett D \& Narayan P 2005 Gonadal defects and hormonal alterations in transgenic mice expressing a single chain human chorionic gonadotropin-lutropin receptor complex. Journal of Molecular Endocrinology 34 489-503. (doi:10.1677/jme.1.01669)

Meng H, Zhang X, Hankenson KD \& Wang MM 2009 Thrombospondin 2 potentiates notch3/jagged1 signaling. Journal of Biological Chemistry 284 7866-7874. (doi:10.1074/jbc.M803650200)

Menke DB, Koubova J \& Page DC 2003 Sexual differentiation of germ cells in XX mouse gonads occurs in an anterior-to-posterior wave. Developmental Biology 262 303-312. (doi:10.1016/S00121606(03)00391-9)

Miyamoto A, Lau R, Hein PW, Shipley JM \& Weinmaster G 2006 Microfibrillar proteins MAGP-1 and MAGP-2 induce Notch1 extracellular domain dissociation and receptor activation. Journal of Biological Chemistry 281 10089-10097. (doi:10.1074/jbc.M600298200)

Monahan P, Rybak S \& Raetzman LT 2009 The notch target gene HES1 regulates cell cycle inhibitor expression in the developing pituitary. Endocrinology 150 4386-4394. (doi:10.1210/en.2009-0206)

Mukherjee A, Veraksa A, Bauer A, Rosse C, Camonis J \& ArtavanisTsakonas S 2005 Regulation of Notch signalling by non-visual betaarrestin. Nature Cell Biology 7 1191-1201. (doi:10.1038/ncb1327)

Mullendore ME, Koorstra JB, Li YM, Offerhaus GJ, Fan X, Henderson CM, Matsui W, Eberhart CG, Maitra A \& Feldmann G 2009 Liganddependent Notch signaling is involved in tumor initiation and tumor maintenance in pancreatic cancer. Clinical Cancer Research 15 2291-2301. (doi:10.1158/1078-0432.CCR-08-2004)

Mumm JS \& Kopan R 2000 Notch signaling: from the outside in. Developmental Biology 228 151-165. (doi:10.1006/dbio.2000.9960)

Murta D, Batista M, Silva E, Trindade A, Mateus L, Duarte A \& Lopesda-Costa L 2014 Differential expression of Notch component and effector genes during ovarian follicle and corpus luteum development during the oestrous cycle. Reproduction Fertility and Development 27 1038-1048

Nagaraja AK, Andreu-Vieyra C, Franco HL, Ma L, Chen R, Han DY, Zhu H, Agno JE, Gunaratne PH, DeMayo FJ et al. 2008 Deletion of Dicer in somatic cells of the female reproductive tract causes sterility. Molecular Endocrinology 22 2336-2352. (doi:10.1210/me.2008-0142)

Nickoloff BJ, Qin JZ, Chaturvedi V, Denning MF, Bonish B \& Miele L 2002 Jagged-1 mediated activation of notch signaling induces complete maturation of human keratinocytes through NF-kappaB and PPARgamma. Cell Death and Differentiation 9 842-855. (doi:10.1038/ sj.cdd.4401036)

Nilsson EE, Stanfield J \& Skinner MK 2006 Interactions between progesterone and tumor necrosis factor-alpha in the regulation of primordial follicle assembly. Reproduction 132 877-886. (doi:10.1530/ REP-06-0045)

Oda T, Elkahloun AG, Pike BL, Okajima K, Krantz ID, Genin A, Piccoli DA, Meltzer PS, Spinner NB, Collins FS et al. 1997 Mutations in the human Jagged1 gene are responsible for Alagille syndrome. Nature Genetics 16 235-242. (doi:10.1038/ng0797-235)

Pan Z, Sun M, Li J, Zhou F, Liang X, Huang J, Zheng T, Zheng L \& Zheng Y 2015 The expression of markers related to ovarian germline stem cells in the mouse ovarian surface epithelium and the correlation with notch signaling pathway. Cellular Physiology and Biochemistry 37 2311-2322. (doi:10.1159/000438586)
Pangas SA, Jorgez CJ, Tran M, Agno J, Li X, Brown CW, Kumar TR \& Matzuk MM 2007 Intraovarian activins are required for female fertility. Molecular Endocrinology 21 2458-2471. (doi:10.1210/me.2007-0146)

Park JT, Chen X, Trope CG, Davidson B, Shih Ie M \& Wang TL 2010 Notch3 overexpression is related to the recurrence of ovarian cancer and confers resistance to carboplatin. American Journal of Pathology 177 1087-1094. (doi:10.2353/ajpath.2010.100316)

Penton AL, Leonard LD \& Spinner NB 2012 Notch signaling in human development and disease. Seminars in Cell and Developmental Biology 23 450-457. (doi:10.1016/j.semcdb.2012.01.010)

Pepling ME 2012 Follicular assembly: mechanisms of action. Reproduction 143 139-149. (doi:10.1530/REP-11-0299)

Pepling ME \& Spradling AC 1998 Female mouse germ cells form synchronously dividing cysts. Development 125 3323-3328.

Pepling ME \& Spradling AC 2001 Mouse ovarian germ cell cysts undergo programmed breakdown to form primordial follicles. Developmental Biology 234 339-351. (doi:10.1006/dbio.2001.0269)

Raetzman LT, Wheeler BS, Ross SA, Thomas PQ \& Camper SA 2006 Persistent expression of Notch2 delays gonadotrope differentiation. Molecular Endocrinology 20 2898-2908. (doi:10.1210/me.2005-0394)

Rajkovic A, Pangas SA, Ballow D, Suzumori N \& Matzuk MM 2004 NOBOX deficiency disrupts early folliculogenesis and oocyte-specific gene expression. Science 305 1157-1159. (doi:10.1126/science.1099755)

Rauen T, Raffetseder U, Frye BC, Djudjaj S, Muhlenberg PJ, Eitner F, Lendahl U, Bernhagen J, Dooley S \& Mertens PR 2009 YB-1 acts as a ligand for Notch-3 receptors and modulates receptor activation. Journal of Biological Chemistry 284 26928-26940. (doi:10.1074/jbc. M109.046599)

Reedijk M, Odorcic S, Zhang H, Chetty R, Tennert C, Dickson BC, Lockwood G, Gallinger S \& Egan SE 2008 Activation of Notch signaling in human colon adenocarcinoma. International Journal of Oncology 33 1223-1229. (doi:10.3892/ijo_00000112)

Risma KA, Clay CM, Nett TM, Wagner T, Yun J \& Nilson JH 1995 Targeted overexpression of luteinizing hormone in transgenic mice leads to infertility, polycystic ovaries, and ovarian tumors. PNAS 92 1322-1326. (doi:10.1073/pnas.92.5.1322)

Risma KA, Hirshfield AN \& Nilson JH 1997 Elevated luteinizing hormone in prepubertal transgenic mice causes hyperandrogenemia, precocious puberty, and substantial ovarian pathology. Endocrinology 138 3540-3547. (doi:10.1210/en.138.8.3540)

Rose SL 2009 Notch signaling pathway in ovarian cancer. International Journal of Gynecological Cancer 19 564-566. (doi:10.1111/ IGC.0b013e3181a12ed2)

Rose SL, Kunnimalaiyaan M, Drenzek J \& Seiler N 2010 Notch 1 signaling is active in ovarian cancer. Gynecologic Oncology 117 130-133. (doi:10.1016/j.ygyno.2009.12.003)

Sahebjam S, Bedard PL, Castonguay V, Chen Z, Reedijk M, Liu G, Cohen B, Zhang WJ, Clarke B, Zhang T et al. 2013 A phase I study of the combination of ro4929097 and cediranib in patients with advanced solid tumours (PJC-004/NCl 8503). British Journal of Cancer 109 943-949. (doi:10.1038/bjc.2013.380)

Sainson RC, Aoto J, Nakatsu MN, Holderfield M, Conn E, Koller E \& Hughes CC 2005 Cell-autonomous notch signaling regulates endothelial cell branching and proliferation during vascular tubulogenesis. FASEB Journal 19 1027-1029. (doi:10.1096/fj.04-3172fje)

Saitou M \& Yamaji M 2012 Primordial germ cells in mice. Cold Spring Harbor Perspectives in Biology 4 a008375. (doi:10.1101/cshperspect. a008375)

Sakamoto K, Yamaguchi S, Ando R, Miyawaki A, Kabasawa Y, Takagi M, Li CL, Perbal B \& Katsube K 2002 The nephroblastoma overexpressed gene (NOV/ccn3) protein associates with Notch1 extracellular domain and inhibits myoblast differentiation via Notch signaling pathway. Journal of Biological Chemistry 277 29399-29405. (doi:10.1074/jbc. M203727200)

Saxena MT, Schroeter EH, Mumm JS \& Kopan R 2001 Murine notch homologs (N1-4) undergo presenilin-dependent proteolysis. Journal of Biological Chemistry 276 40268-40273. (doi:10.1074/jbc.M107234200)

Schmidt MH, Bicker F, Nikolic I, Meister J, Babuke T, Picuric S, MullerEsterl W, Plate KH \& Dikic I 2009 Epidermal growth factor-like domain 7 (EGFL7) modulates Notch signalling and affects neural stem cell renewal. Nature Cell Biology 11 873-880. (doi:10.1038/ncb1896) 
Schweisguth F 2004 Regulation of notch signaling activity. Current Biology 14 R129-R138. (doi:10.1016/j.cub.2004.01.023)

Shah MM, Zerlin M, Li BY, Herzog TJ, Kitajewski JK \& Wright JD 2013 The role of Notch and gamma-secretase inhibition in an ovarian cancer model. Anticancer Research 33 801-808.

Shimizu K, Chiba S, Kumano K, Hosoya N, Takahashi T, Kanda Y, Hamada Y, Yazaki Y \& Hirai H 1999 Mouse jagged1 physically interacts with notch2 and other notch receptors. Assessment by quantitative methods. Journal of Biological Chemistry 274 32961-32969. (doi:10.1074/ jbc.274.46.32961)

Shimizu K, Chiba S, Hosoya N, Kumano K, Saito T, Kurokawa M, Kanda Y, Hamada Y \& Hirai H 2000a Binding of Delta1, Jagged1, and Jagged2 to Notch2 rapidly induces cleavage, nuclear translocation, and hyperphosphorylation of Notch2. Molecular and Cellular Biology 20 6913-6922. (doi:10.1128/MCB.20.18.6913-6922.2000)

Shimizu K, Chiba S, Saito T, Kumano K \& Hirai H 2000b Physical interaction of Delta1, Jagged1, and Jagged2 with Notch1 and Notch3 receptors. Biochemical and Biophysical Research Communications 276 385-389. (doi:10.1006/bbrc.2000.3469)

Silva-Santos K \& Seneda M 2011 Multioocyte follicles in adult mammalian ovaries. Animal Reproduction 8 58-67.

Simon AM, Goodenough DA, Li E \& Paul DL 1997 Female infertility in mice lacking connexin 37. Nature 385 525-529. (doi:10.1038/385525a0)

Simpson MA, Irving MD, Asilmaz E, Gray MJ, Dafou D, Elmslie FV, Mansour S, Holder SE, Brain CE, Burton BK et al. 2011 Mutations in NOTCH2 cause Hajdu-Cheney syndrome, a disorder of severe and progressive bone loss. Nature Genetics 43 303-305. (doi:10.1038/ng.779)

Soyal SM, Amleh A \& Dean J 2000 FIGalpha, a germ cell-specific transcription factor required for ovarian follicle formation. Development 127 4645-4654.

Spears N, Molinek MD, Robinson LL, Fulton N, Cameron H, Shimoda K, Telfer EE, Anderson RA \& Price DJ 2003 The role of neurotrophin receptors in female germ-cell survival in mouse and human. Development $\mathbf{1 3 0}$ 5481-5491. (doi:10.1242/dev.00707)

Stittrich AB, Lehman A, Bodian DL, Ashworth J, Zong Z, Li H, Lam P, Khromykh A, Iyer RK, Vockley JG et al. 2014 Mutations in NOTCH1 cause Adams-Oliver syndrome. American Journal of Human Genetics 95 275-284. (doi:10.1016/j.ajhg.2014.07.011)

Tang H, Brennan J, Karl J, Hamada Y, Raetzman L \& Capel B 2008 Notch signaling maintains Leydig progenitor cells in the mouse testis. Development 135 3745-3753. (doi:10.1242/dev.024786)

Tanriverdi G, Denir S, Ayla S, Bilir A, Oktar H, Cepni I \& Irez T 2013 Notch signaling pathway in cumulus cells can be a novel marker to identify poor and normal responder IVF patients. Journal of Assisted Reproduction and Genetics 30 1319-1326. (doi:10.1007/s10815-0130072-4)

Teng Z, Wang C, Wang Y, Huang K, Xiang X, Niu W, Feng L, Zhao L, Yan H \& Zhang H 2016 Gap junctions are essential for murine primordial follicle assembly immediately before birth. Reproduction 151 105-115. (doi:10.1530/REP-15-0282)

Terauchi KJ, Shigeta Y, Iguchi T \& Sato T 2016 Role of Notch signaling in granulosa cell proliferation and polyovular follicle induction during folliculogenesis in mouse ovary. Cell and Tissue Research 365 197-208. (doi:10.1007/s00441-016-2371-4)

Torres IL, Lopez-Schier H \& St Johnston D 2003 A Notch/Delta-dependent relay mechanism establishes anterior-posterior polarity in Drosophila. Developmental Cell 5 547-558. (doi:10.1016/S1534-5807(03)00272-7)

Trombly DJ, Woodruff TK \& Mayo KE 2009a Roles for transforming growth factor beta superfamily proteins in early folliculogenesis. Seminars in Reproductive Medicine 27 14-23. (doi:10.1055/s-0028-1108006)

Trombly DJ, Woodruff TK \& Mayo KE 2009b Suppression of Notch signaling in the neonatal mouse ovary decreases primordial follicle formation. Endocrinology 150 1014-1024. (doi:10.1210/en.2008-0213)

Vainio S, Heikkila M, Kispert A, Chin N \& McMahon AP 1999 Female development in mammals is regulated by Wnt-4 signalling. Nature 397 405-409. (doi:10.1038/17068)

Vanorny DA 2016 Notch Signaling during Ovarian Follicle Formation and Development PhD thesis. Northwestern University, USA.
Vanorny DA, Prasasya RD, Chalpe AJ, Kilen SM \& Mayo KE 2014 Notch signaling regulates ovarian follicle formation and coordinates follicular growth. Molecular Endocrinology 28 499-511. (doi:10.1210/me.20131288)

Vorontchikhina MA, Zimmermann RC, Shawber CJ, Tang H \& Kitajewski J 2005 Unique patterns of Notch1, Notch4 and Jagged1 expression in ovarian vessels during folliculogenesis and corpus luteum formation. Gene Expression Patterns 5 701-709. (doi:10.1016/j. modgep.2005.02.001)

Walters Haygood CL, Arend RC, Straughn JM \& Buchsbaum DJ 2014 Ovarian cancer stem cells: can targeted therapy lead to improved progression-free survival? World Journal of Stem Cells 6 441-447. (doi:10.4252/wjsc.v6.i4.441)

Wang LQ, Liu JC, Chen CL, Cheng SF, Sun XF, Zhao Y, Yin S, Hou ZM, Pan B, Ding C et al. 2014 Regulation of primordial follicle recruitment by cross-talk between the Notch and phosphatase and tensin homologue (PTEN)/AKT pathways. Reproduction Fertility and Development 28 700-712. (doi:10.1071/RD14212)

Wang J, Liu S, Peng L, Dong Q, Bao R, Lv Q, Tang M, Hu C, Li G, Liang $\mathbf{S}$ et al. 2015 Notch signaling pathway regulates progesterone secretion in murine luteal cells. Reproductive Sciences 22 1243-1251. (doi:10.1177/1933719115572480)

Weijzen S, Velders MP, Elmishad AG, Bacon PE, Panella JR, Nickoloff BJ, Miele L \& Kast WM 2002 The Notch ligand Jagged-1 is able to induce maturation of monocyte-derived human dendritic cells. Journal of Immunology 169 4273-4278. (doi:10.4049/jimmunol.169.8.4273)

Weng AP, Ferrando AA, Lee W, Morris JPt, Silverman LB, SanchezIrizarry C, Blacklow SC, Look AT \& Aster JC 2004 Activating mutations of NOTCH1 in human T cell acute lymphoblastic leukemia. Science 306 269-271. (doi:10.1126/science.1102160)

Xu J 2011 Notch Function in Mouse Folliculogenesis Electronic Theses and Dissertations. 1741. University of Maine, USA (http: //digitalcommons. library.umaine.edu/etd/1741).

Xu J \& Gridley T 2013 Notch2 is required in somatic cells for breakdown of ovarian germ-cell nests and formation of primordial follicles. BMC Biology 11 13. (doi:10.1186/1741-7007-11-13)

Xu J, Norton CR \& Gridley T 2006 Not all lunatic fringe null female mice are infertile. Development 133 579; author reply 579-580. (doi:10.1242/ dev.02221)

Xu B, Zhang YW, Tong XH \& Liu YS 2015 Characterization of microRNA profile in human cumulus granulosa cells: Identification of microRNAs that regulate Notch signaling and are associated with PCOS. Molecular and Cellular Endocrinology $\mathbf{4 0 4}$ 26-36. (doi:10.1016/j.mce.2015.01.030)

Xue Y, Gao X, Lindsell CE, Norton CR, Chang B, Hicks C, GendronMaguire M, Rand EB, Weinmaster G \& Gridley T 1999 Embryonic lethality and vascular defects in mice lacking the Notch ligand Jagged1. Human Molecular Genetics 8 723-730. (doi:10.1093/hmg/8.5.723)

Zhang H \& Liu K 2015 Cellular and molecular regulation of the activation of mammalian primordial follicles: somatic cells initiate follicle activation in adulthood. Human Reproduction Update 21 779-786. (doi:10.1093/ humupd/dmv037)

Zhang CP, Yang JL, Zhang J, Li L, Huang L, Ji SY, Hu ZY, Gao F \& Liu YX 2011 Notch signaling is involved in ovarian follicle development by regulating granulosa cell proliferation. Endocrinology 152 2437-2447. (doi:10.1210/en.2010-1182)

Zhao L, Du X, Huang K, Zhang T, Teng Z, Niu W, Wang C \& Xia G 2016 Rac1 modulates the formation of primordial follicles by facilitating STAT3-directed Jagged1, GDF9 and BMP15 transcription in mice. Scientific Reports 6 23972. (doi:10.1038/srep23972)

Received 27 December 2016

First decision 3 February 2017

Revised manuscript received 3 March 2017

Accepted 9 March 2017 